\title{
A Densified Liquid Methane Delivery System for the Altair Ascent Stage
}

Thomas M. Tomsik

Glenn Research Center, Cleveland, Ohio

Wesley L. Johnson, Todd D. Smudde, and Mark F. Femminineo

Kennedy Space Center, Kennedy Space Center, Florida

Andrew R. Schnell

Marshall Space Flight Center, Huntsville, Alabama 


\section{NASA STI Program ... in Profile}

Since its founding, NASA has been dedicated to the advancement of aeronautics and space science. The NASA Scientific and Technical Information (STI) program plays a key part in helping NASA maintain this important role.

The NASA STI Program operates under the auspices of the Agency Chief Information Officer. It collects, organizes, provides for archiving, and disseminates NASA's STI. The NASA STI program provides access to the NASA Aeronautics and Space Database and its public interface, the NASA Technical Reports Server, thus providing one of the largest collections of aeronautical and space science STI in the world. Results are published in both non-NASA channels and by NASA in the NASA STI Report Series, which includes the following report types:

- TECHNICAL PUBLICATION. Reports of completed research or a major significant phase of research that present the results of NASA programs and include extensive data or theoretical analysis. Includes compilations of significant scientific and technical data and information deemed to be of continuing reference value. NASA counterpart of peer-reviewed formal professional papers but has less stringent limitations on manuscript length and extent of graphic presentations.

- TECHNICAL MEMORANDUM. Scientific and technical findings that are preliminary or of specialized interest, e.g., quick release reports, working papers, and bibliographies that contain minimal annotation. Does not contain extensive analysis.

- CONTRACTOR REPORT. Scientific and technical findings by NASA-sponsored contractors and grantees.
- CONFERENCE PUBLICATION. Collected papers from scientific and technical conferences, symposia, seminars, or other meetings sponsored or cosponsored by NASA.

- SPECIAL PUBLICATION. Scientific, technical, or historical information from NASA programs, projects, and missions, often concerned with subjects having substantial public interest.

- TECHNICAL TRANSLATION. Englishlanguage translations of foreign scientific and technical material pertinent to NASA's mission.

Specialized services also include creating custom thesauri, building customized databases, organizing and publishing research results.

For more information about the NASA STI program, see the following:

- Access the NASA STI program home page at http://www.sti.nasa.gov

- E-mail your question via the Internet to help@ sti.nasa.gov

- Fax your question to the NASA STI Help Desk at 443-757-5803

- Telephone the NASA STI Help Desk at 443-757-5802

- Write to: NASA Center for AeroSpace Information (CASI) 7115 Standard Drive Hanover, MD 21076-1320 


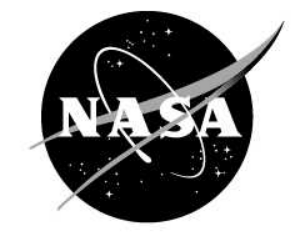

\section{A Densified Liquid Methane Delivery System for the Altair Ascent Stage}

Thomas M. Tomsik

Glenn Research Center, Cleveland, Ohio

Wesley L. Johnson, Todd D. Smudde, and Mark F. Femminineo

Kennedy Space Center, Kennedy Space Center, Florida

Andrew R. Schnell

Marshall Space Flight Center, Huntsville, Alabama

Prepared for the

SpaceOps 2010 Conference

sponsored by the American Institute of Aeronautics and Astronautics

Huntsville, Alabama, April 25-30, 2010

National Aeronautics and

Space Administration

Glenn Research Center

Cleveland, Ohio 44135 
Level of Review: This material has been technically reviewed by technical management.

Available from

NASA Center for Aerospace Information 7115 Standard Drive

Hanover, MD 21076-1320
National Technical Information Service 5301 Shawnee Road Alexandria, VA 22312

Available electronically at http://gltrs.grc.nasa.gov 


\title{
A Densified Liquid Methane Delivery System for the Altair Ascent Stage
}

\author{
Thomas M. Tomsik \\ National Aeronautics and Space Administration \\ Glenn Research Center \\ Cleveland, Ohio 44135 \\ Wesley L. Johnson, Todd D. Smudde, and Mark F. Femminineo \\ National Aeronautics and Space Administration \\ Kennedy Space Center \\ Kennedy Space Center, Florida 32899 \\ Andrew R. Schnell \\ National Aeronautics and Space Administration \\ Marshall Space Flight Center \\ Huntsville, Alabama 35812
}

\begin{abstract}
The Altair Lunar Lander is currently carrying options for both cryogenic and hypergolic ascent stage propulsion modules. The cryogenic option uses liquid methane and liquid oxygen to propel Altair from the lunar surface back to rendezvous with the Orion command module. Recent studies have determined that the liquid methane should be densified by subcooling it to $93 \mathrm{~K}$ in order to prevent overpressurization of the propellant tanks during the 210 day stay on the lunar surface. A trade study has been conducted to determine the preferred method of producing, loading, and maintaining the subcooled, densified liquid methane onboard Altair from a ground operations perspective. The trade study took into account the limitations in mass for the launch vehicle and the mobile launch platform as well as the historical reliability of various components and their thermal efficiencies. Several unique problems were encountered, namely delivering a small amount of a cryogenic propellant to a flight tank that's positioned over $350 \mathrm{ft}$ above the launch pad as well as generating the desired delivery temperature of the methane at $93 \mathrm{~K}$ which is only $2.3 \mathrm{~K}$ above the methane triple point of $90.7 \mathrm{~K}$. Over 20 methods of subcooled liquid methane production and delivery along with the associated system architectures were investigated to determine the best solutions to the problem. The top four cryogenic processing solutions were selected for further evaluation and detailed thermal modeling. This paper describes the results of the preliminary trade analysis of the 20 plus methane densification methods considered. The results of the detailed analysis will be briefed to the Altair Project Office and their propulsion team as well as the Ground Operations Project Office before the down-select is made between cryogenic and hypergolic ascent stages in August 2010.
\end{abstract}

\section{Introduction}

Densified propellants have frequently been identified and studied as a viable approach for substantial mass savings on launch vehicles as well as alleviating long duration cryogenic storage system (Refs. 1 to 5) problems. Several different densification systems were proposed for the Space Shuttle's liquid oxygen and liquid hydrogen external propellant tanks (Ref. 6). Densified propellant systems were never implemented however for actual use in Shuttle operations (Ref. 7). The interest in the technology remained keen though, and propellant conditioning systems were designed, built and demonstrated in the 1990s. For example, large scale densification units were developed for handling liquid hydrogen and liquid oxygen for the X-33 Reusable Launch Vehicle program (Refs. 8 to 10). Figure 1 shows the X-33 


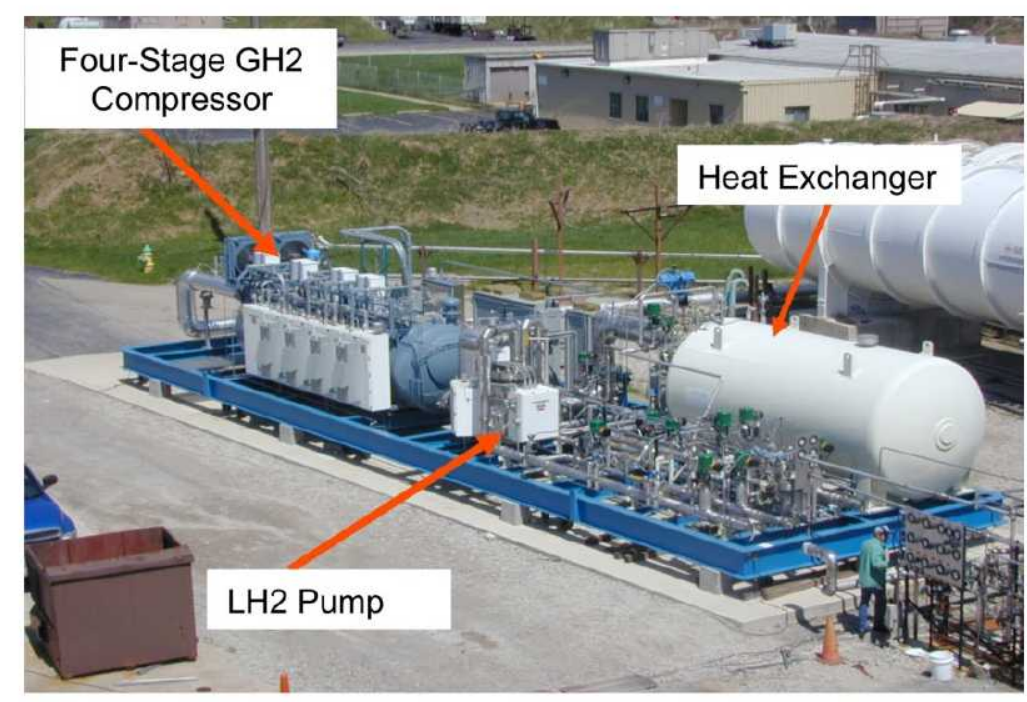

Figure 1.-X-33 liquid hydrogen propellant densification unit demonstration at the NASA Glenn Research Center S40 Test Facility.

LH2 propellant densification skid at a NASA test facility. The unit was designed to process $800 \mathrm{gpm}$ of densified LH2. Different approaches and alternative cryogenic systems were similarly proposed by others in the aerospace community for the Second Generation Launch Vehicle and Next Generation Launch System projects (Refs. 11 to 13). The mass savings benefit for such a propulsion system carrying densified propellants can vary from as high as 20 percent reduction in launch vehicle mass at gross lift-off to nearly a few percent, albeit a very significant few percent. In general compared to liquid methane, liquid hydrogen becomes more difficult to densify in a practical method (Ref. 14) due to its very low normal boiling point $(20 \mathrm{~K})$ and thus would drive the requirement for even lower temperatures for densification.

NASA's Constellation program has several propulsion systems that are candidates for propellant densification. The best candidate is the liquid methane/liquid oxygen ascent stage of the Altair lunar lander. The densification state condition allows the heat leak that flows into the methane tanks through the struts, penetrations, and multilayer insulation (MLI) during the mission to be absorbed by the subcooled liquid propellant. The propellant undergoes a subsequent rise in temperature but without the need to vent as tank pressure remains approximately constant during this "warm-up" period. Tank pressure will gradually rise within the prescribed design pressure limits of the tank as the propellant nears saturation. Initial CFD modeling studies show that the energy absorbed by the liquid methane over the entire 210 day mission would not exceed the propellant system thermal absorption capacity of the fuel and oxidizer tanks (Ref. 15). Thus a key derived requirement of the cryogenic propellant densification system is to base the design temperature for the production and delivery of $93 \mathrm{~K}$ subcooled liquid methane stored on-board Altair prior to lift-off. A successful design to this requirement enables the development of the mass and performance attributes of a viable cryogenic LOX/LCH4 ascent stage for Altair.

The Altair is to be launched as part of the payload of the Ares V heavy lift launch vehicle. The Ares V will deliver Altair and the Earth Departure Stage to Low Earth Orbit (LEO), where they will meet up with the Orion crew vehicle. The two will rendezvous and dock before the Earth Departure Stage (EDS) is reignited to perform the Trans Lunar Insertion (TLI) segment. The EDS becomes expended then separates from the Lander and as the Lander approaches the Moon, it performs the Lunar Orbit Insertion (LOI) maneuver as illustrated in Figure 2. 


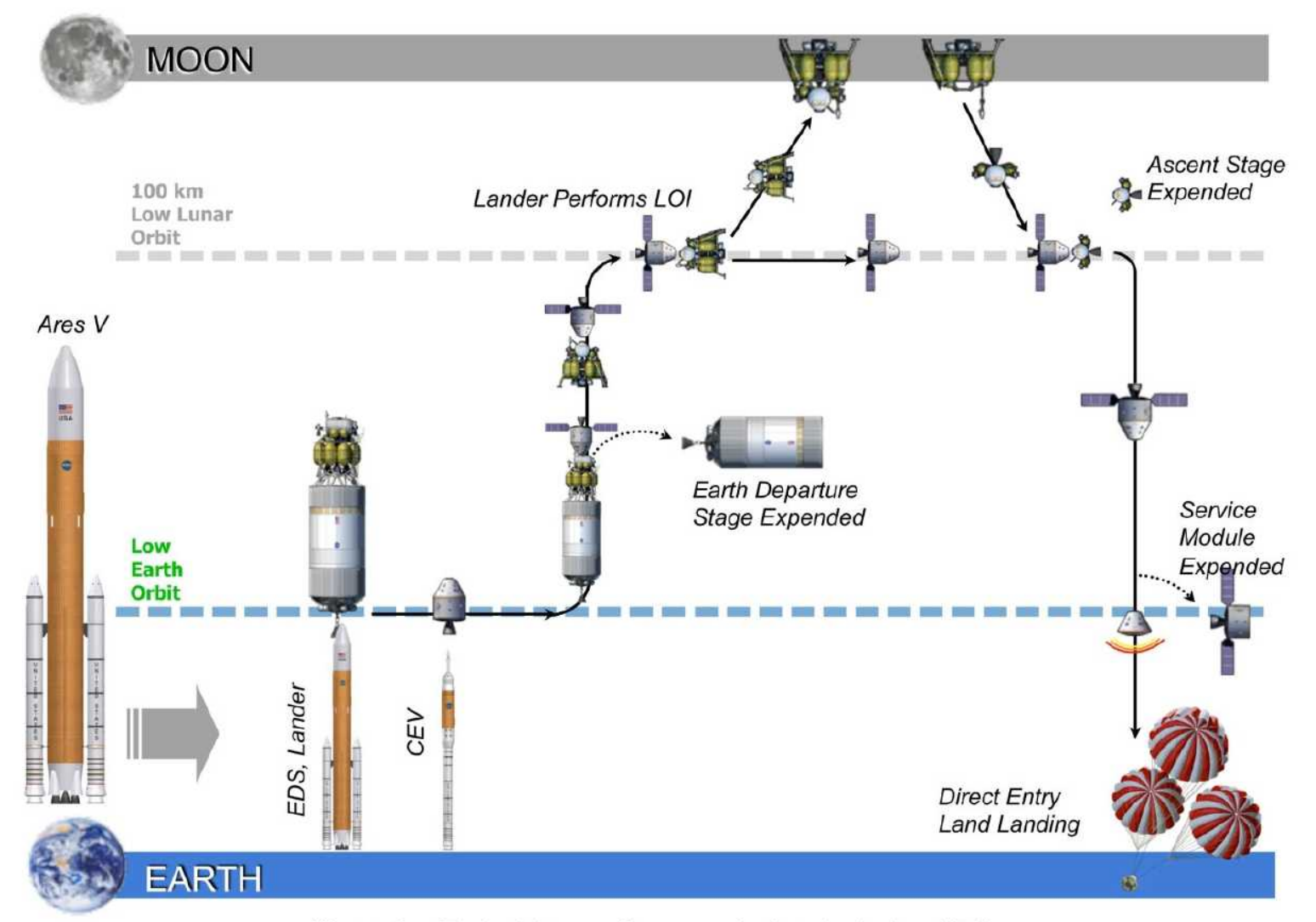

Figure 2.-Typical lunar reference mission deploying Altair.

Currently the Ares V is over $100 \mathrm{~m}$ tall, and is limited in height by the Vehicle Assembly Building (VAB) at the Kennedy Space Center, where the Ares V will be assembled. The servicing of the cryogenic ascent stage will have to be done at a height of approximately $100 \mathrm{~m}$ unless a method can be conceived to allow for the storage vessel and transfer system to be located on the actual vehicle access/umbilical tower. Historically, cryogenic propellants have been transferred to the launch vehicle from extremely large LH2/LOX spherical storage dewars that are located over $500 \mathrm{~m}$ away from the actual launch pad. In this operation, several thousand cubic meters of NBP propellant can be delivered to the launch vehicle. For the very small amounts of propellant required by Altair (a total on-board fuel volume of only $1.82 \mathrm{~m}^{3}$ ) this would be an extremely inefficient and impractical method of propellant delivery. The remote delivery approach would in-turn impact system performance and would likely cause the cost of the delivery of the propellants to negate any advantages gained by them.

A schematic of the Ares V Launch Pad, shown in Figure 3, indicates the relative elevations and possible locations for a methane conditioning system. The Altair umbilical is about $100 \mathrm{~m}(328 \mathrm{ft})$ above the Mobile Launch Platform (MLP) while the Launch pad surface is $12 \mathrm{~m}$ (40 ft) above existing bulk LOX/LH2 propellant storage tanks. This paper describes the results of a trade analysis made between 26 different conceptual methane densification processes for producing and delivering $1.82 \mathrm{~m}^{3}$ of subcooled liquid methane (LCH4) at $93 \mathrm{~K}$ to support Altairs' mission to the Moon. 


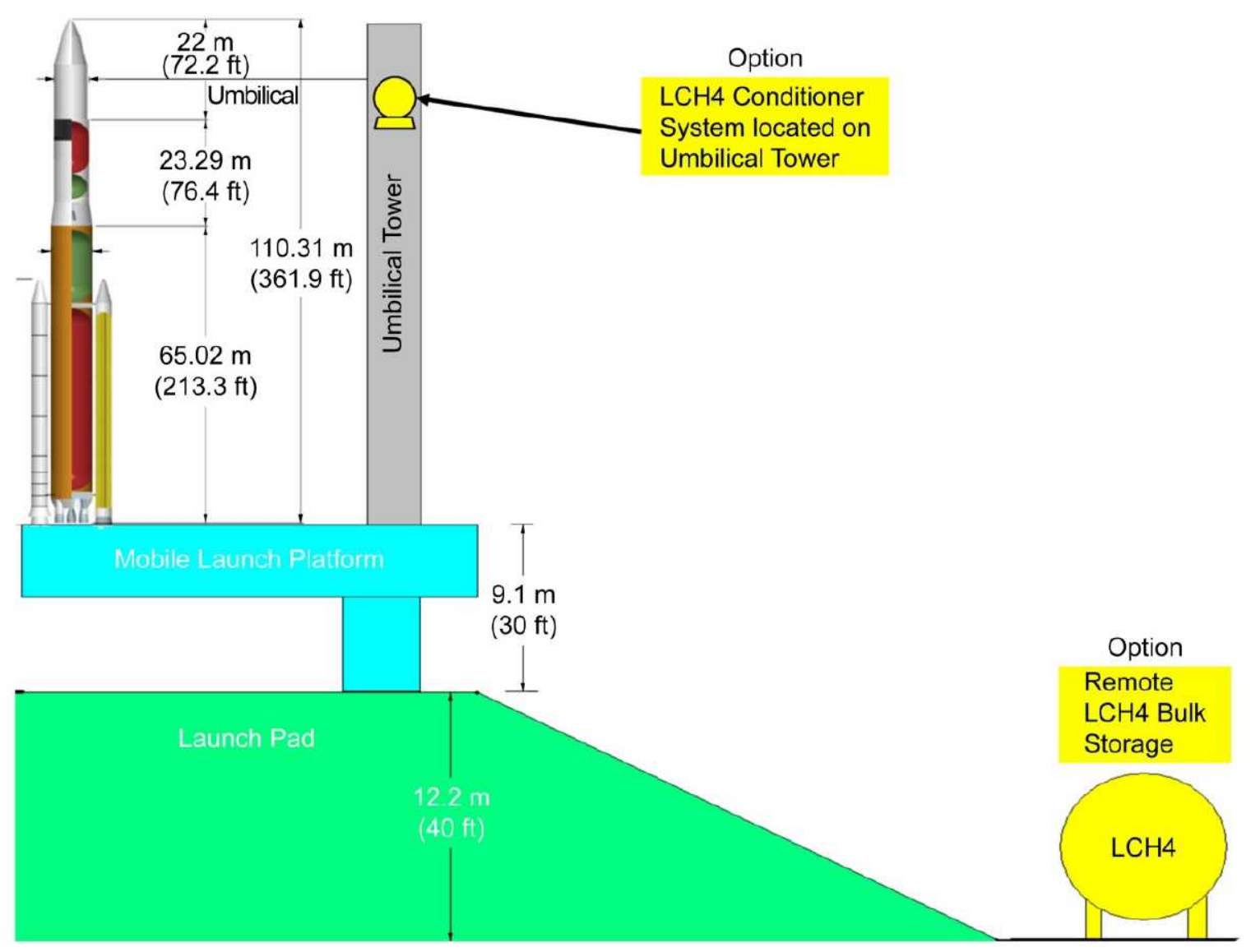

Figure 3.-Ares $\vee$ launch pad schematic (not to scale).

\section{Nomenclature}

$\begin{array}{ll}\text { AIAA } & \text { American Institute of Aeronautics and Astronautics } \\ \text { CFD } & \text { Computational Fluid Dynamics } \\ \text { CFM } & \text { Cryogenic Fluid Management } \\ \text { EDS } & \text { Earth Departure Stage } \\ \text { ETDP } & \begin{array}{l}\text { Exploration Technology Development Program } \\ \text { ethylene tetroxide }\end{array} \\ \text { ETO } & \text { gaseous helium } \\ \text { GHe } & \text { NASA Glenn Research Center } \\ \text { GRC } & \text { Ground Support Equipment } \\ \text { GSE } & \text { Specific Impulse } \\ \text { ISP } & \text { Joule-Thompson } \\ \text { JT } & \text { NASA Kennedy Space Center } \\ \text { KSC } & \text { liquid argon } \\ \text { LAr } & \text { liquid methane } \\ \text { LCH4 } & \text { Low Earth Orbit } \\ \text { LEO } & \text { liquid hydrogen } \\ \text { LH2 } & \text { liquid nitrogen } \\ \text { LN2 } & \text { Lunar Orbit Insertion }\end{array}$




$\begin{array}{ll}\text { LOX } & \text { liquid oxygen } \\ \text { LSS } & \text { Lunar Surface Systems } \\ \text { LUT } & \text { Launch Umbilical Tower } \\ \text { MAWP } & \text { Maximum Allowable Working Pressure } \\ \text { MEOP } & \text { Maximum Expected Operating Pressure } \\ \text { MLI } & \text { Multi-Layer Insulation } \\ \text { MLP } & \text { Mobile Launch Platform } \\ \text { MMH } & \text { monomethyl hydrazine } \\ \text { MSFC } & \text { NASA Marshall Space Flight Center } \\ \text { NASA } & \text { National Aeronautics and Space Administration } \\ \text { NBP } & \text { Normal Boiling Point } \\ \text { RLV } & \text { Reusable Launch Vehicle } \\ \text { SMiRF } & \text { Small Multi-Purpose Research Facility } \\ \text { SLCH4 } & \text { slush methane } \\ \text { TLI } & \text { Trans Lunar Insertion } \\ \text { TRL } & \text { Technology Readiness Level } \\ \text { TVS } & \text { Thermodynamic Vent System } \\ \text { VAB } & \text { Vehicle Assembly Building } \\ \text { VJ } & \text { Vacuum Jacketed }\end{array}$

\section{Altair Ascent Stage Design Requirements}

The fuel tanks to be serviced by the densification system are the two liquid methane tanks mounted on the ascent stage of the Altair, as shown in Figure 4. The spherical methane tanks are on the side of the crew compartment, each paired with a liquid oxygen tank above it. The tanks will be serviced from the launch umbilical tower that is built onto the mobile launch platform as depicted in Figure 5. There are two spherical liquid methane tanks each of $1.3 \mathrm{~m}$ diameter and volume of $1.07 \mathrm{~m}^{3}$. Each tank is to be 85 percent full to allow for the thermal expansion of the propellant as it warms-up during the mission. This means that for two tanks, a total of $820 \mathrm{~kg}$ of subcooled liquid methane must be delivered to the vehicle.
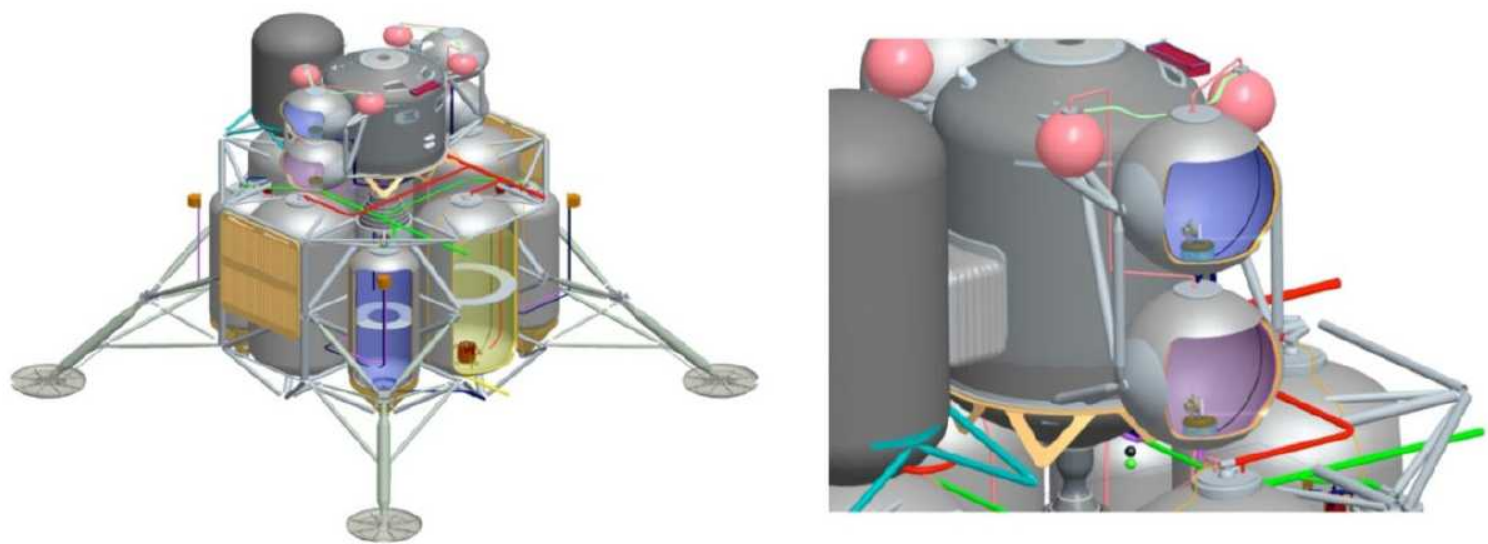

Figure 4.-Typical cryogenic ascent stage on Altair, spherical liquid methane tanks have purple interior. 


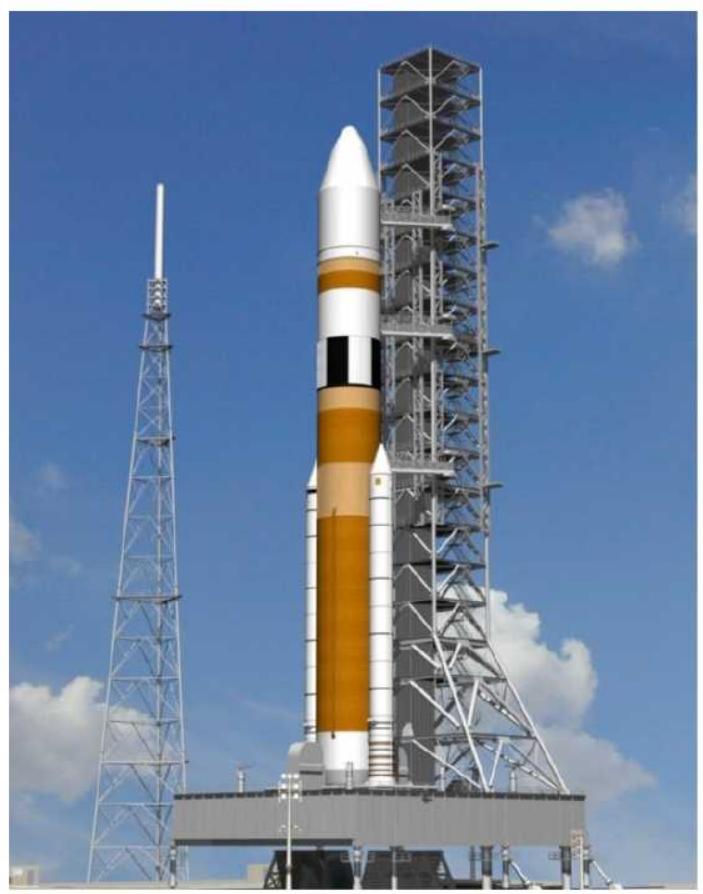

Figure 5.-Ares $V$ and Altair on the launch pad next to the launch umbilical tower.

The thermal CFD analysis (Ref. 15) behind the LCH4 temperature requirement neglected transient heating before reaching steady state in Low Earth Orbit (LEO). Prior to this condition being met, the spacecraft must start off in the ambient atmosphere on the launch pad and be propelled to LEO, meanwhile the transition that takes place with the MLI from 760 torr to $10^{-5}$ torr is a very dynamic transition. Previous testing has shown that the effects of this transition, that's akin to "out-gassing" of the MLI, can take from 24 to $48 \mathrm{hr}$ to run their course before steady state is achieved within the propellant tanks. Lumped parameter models developed by Johnson (Ref. 16) have shown that this thermal transition can generate a propellant temperature increase of at least $0.5 \mathrm{~K}$. Thus this study has assumed that the delivery of the LCH4 propellant shall be at $92.5 \mathrm{~K}$, so this temperature will be the actual design requirement used. Methane has a normal boiling point (NBP) of $111.7 \mathrm{~K}$ so that the subcooling process requirement must result in a bulk fluid temperature $19.2 \mathrm{~K}$ below the NBP. The Altair ascent stage design requirements considered in the methane delivery system trade study are those as shown summarized in Table 1.

The on-the-pad heat leak of a flight like Altair liquid methane tank with $0.5 \mathrm{in}$. of spray-on foam insulation (SOFI) underneath at least 60 to 80 layers of MLI will be in the range of 175 to $200 \mathrm{~W}$. This takes into account the increasing surface area of each layer of MLI as it's installed on the spherical tank. Such a heat leak is much larger than the on-orbit heat leak of the system due to the effects of gas conduction at ambient pressure, and in fact it is over two orders of magnitude higher than the expected on-orbit and lunar heat loads per the studies of Fesmire and Cady (Refs. 17 and 18). The effect of LCH4 tank pressure rise taken from the CFD analysis by Moder et al. (Ref. 15) over the course of the 210 day mission is shown in Figure 6. Their results confirm that the tank operating pressure design limits will not be exceeded for the 100 psig helium pre-pressurization case when the tank initially contains subcooled $\mathrm{LCH} 4$ at $96.1 \mathrm{~K}$ at launch. 
TABLE 1.-ALTAIR ASCENT STAGE DESIGN REQUIREMENTS

FOR THE LCH4 CONDITIONER SYSTEM TRADE.

\begin{tabular}{|lc|}
\hline \multicolumn{1}{|c|}{ Fuel Tank Parameter } & Design Requirement \\
\hline MEOP & $2240 \mathrm{kPa}(325 \mathrm{psig})$ \\
MAWP & $3365 \mathrm{kPa}(488 \mathrm{psig})$ \\
Pre-pressurization $(\dagger)$ & $690 \mathrm{kPa}(100 \mathrm{psig})$ \\
Diameter & $1.27 \mathrm{~m}(50 \mathrm{in})$ \\
Volume, empty & $1.07 \mathrm{~m}^{3}\left(37.8 \mathrm{ft}^{3}\right)$ \\
Material of construction & $\mathrm{AL}-2219$ \\
Tank mass, dry & $34 \mathrm{~kg}(75 \mathrm{lb} \mathrm{m})$ \\
Heat Leaks (per tank $\ddagger)$ & $175 \mathrm{~W}$ \\
On-the-Pad & $500 \mathrm{~W}$ \\
Ascent & $1.0 \mathrm{~W}$ \\
On-Orbit and Cruise & $2.0 \mathrm{~W}$ \\
Lunar Surface (Ref. 15) & \\
Loaded Propellant (per tank $\dot{\dagger})$ & $\left.411 \mathrm{~kg}(906 \mathrm{lb})_{\mathrm{m}}\right)$ \\
Mass & $0.91 \mathrm{~m}^{3}\left(32.3 \mathrm{ft}^{3}\right)$ \\
Volume & $92.5 \mathrm{~K}\left(166.5{ }^{\circ} \mathrm{R}\right)$ \\
Temperature & \\
Fluid Interfaces, size/location & $9.5 \mathrm{~mm} / \mathrm{Top}(3 / 8 \mathrm{in})$ \\
Vent & $50.8 \mathrm{~mm} / \mathrm{Bottom}(2 \mathrm{in})$ \\
Fill/Drain & $1.0 \mathrm{hr}$ \\
Propellant conditioning time &
\end{tabular}

$(\dagger)$ Pre-press with "cold" gaseous helium prior to lift-off.

$(\ddagger)$ Ascent stage has two LCH4 fuel tanks on-board.

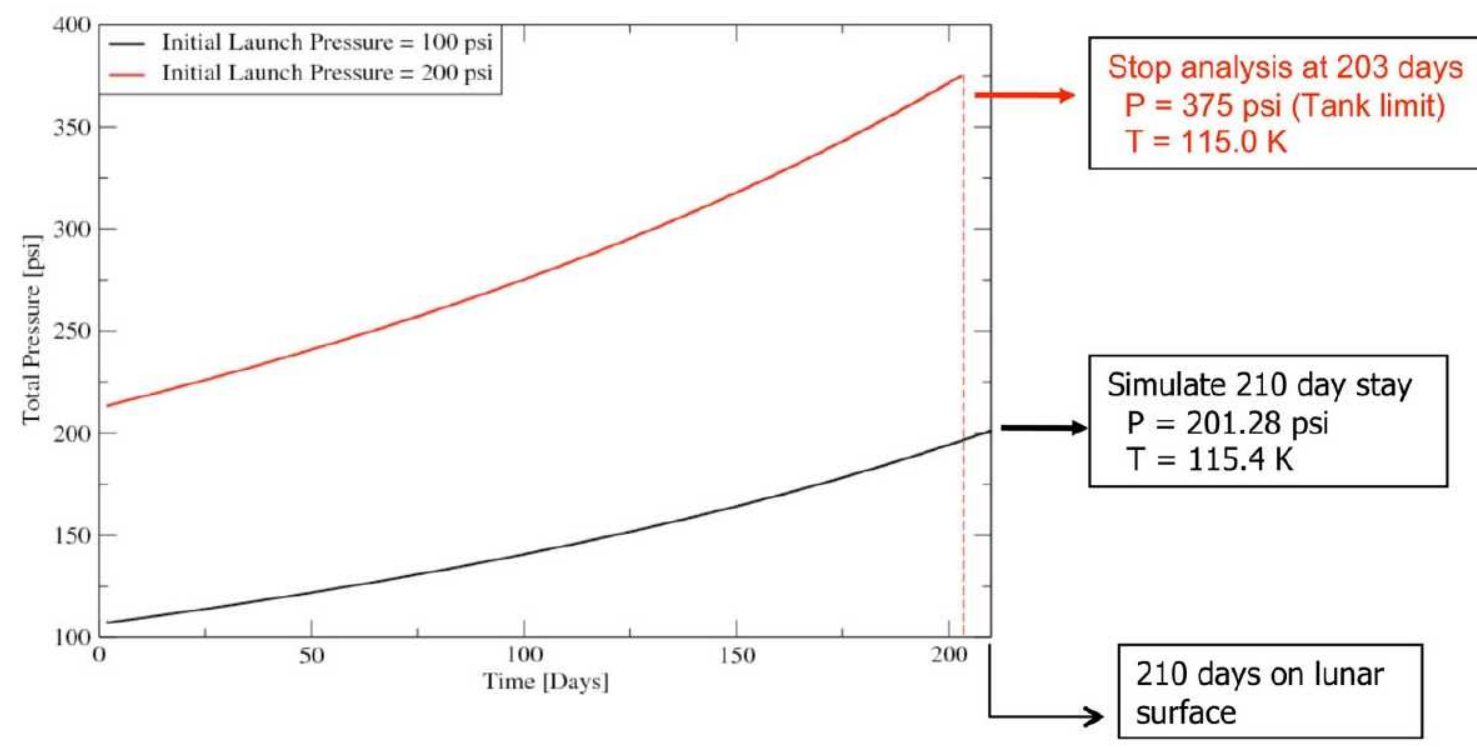

Figure 6.-Long term pressure history for the initially densified LCH4 Altair propellant tank. (Figure duplicated from Ref. 15 with permission from Moder). 


\section{Trade Study Objectives}

The main objective of the study was to determine the best method for producing, transferring and maintaining liquid methane at the required delivery temperature. In order to do that, each method was analyzed thermodynamically using simple spreadsheet models. These models were used to determine or validate the feasibility of the method as well as estimate the approximate mass required on the launch umbilical tower (LUT). Seven metrics were used to determine the ranking of each method relative to the other systems:

1. Safety (SAFETY): A relative measure of the assumed safety of each concept. This is measured in terms of required hazards (to Launch Criteria, GSE, Launch Vehicle, and Personnel) of safety for each concept.

2. Flight Impact (FLTIMPACT): A relative measure of the degree of impact required to the flight system. This impact is measured in terms of thermal, structural, and mass changes to the vehicle.

3. Ground Impact (GRDIMPACT): A relative measure of the degree of impact required on the current or planned ground support equipment. This impact is measured in terms of thermal, structural, and mass additions to the Ground Support Equipment (GSE) such as mass on launch umbilical tower, footprint, etc.

4. Densification Performance (DENSPERF): A measure of the concept's ability to condition the propellant. This is measured in terms of the time required to perform the densification, efficiency, commodity consumption, simplicity, reliability, etc.

5. Implementation Cost (COST): A relative measure of the perceived costs of each concept. The perceived costs will be judged using agency cost estimation guidelines for resources required to operate and maintain the system in an operational environment.

6. Technological Readiness Level (TRL): A NASA defined metric that supports assessments and comparisons of the maturity of a particular technology for spaceflight. The TRL for each delivery system concept will be evaluated based on the NASA guidelines originated by Mankins (Ref. 19).

7. Operations Flexibility (OPFLEX): A relative measure of the dependency of the system on other ground support systems as well as the duration of recovery to be able to support a scrub turnaround.

Each method was scaled between 1 and 10 for each metric, where 10 represents the best or most desirable. The sum of the seven scores gives the total score for the conditioning method. The top three to four highest ranked propellant densification methods will be examined further during a Phase 2 study using greater fidelity thermal models.

A secondary objective of the launch pad densification study was to determine what technology development would need to be done by the Exploration Technology Development Program's (ETDP) Cryogenic Fluid Management (CFM) Project. The CFM project develops technology to TRL level 6, which would involve a "system demonstration in a relevant environment" (Ref. 19). The team examined each of the top methods to determine if any technology development work would need to be done to support the production and loading of densified liquid methane for the Altair ascent stage.

\section{Methane Densification Conceptual Methods}

A total of 26 densification or "propellant conditioning" method architectures were analyzed by the study team. Each of these methods is listed below in Table 2. A simplified schematic was developed for each densification system and these are shown in Figures 8 to 26. Relevant thermophysical properties for liquid methane applied in the spreadsheet system modeling and various analyses are provided for reference in Table 3. 
TABLE 2.-LIQUID METHANE CONDITIONER SYSTEM CONCEPT METHODS EVALUATED IN THE TRADE STUDY

\begin{tabular}{|c|c|}
\hline $\begin{array}{l}\text { Method } \\
\text { No. }\end{array}$ & Description \\
\hline 1 & Low Temperature Gaseous Helium Bubbling \\
\hline 2 & Low Temperature Gaseous Hydrogen Bubbling \\
\hline 3 & Self Densification through a Transfer Pipeline TVS \\
\hline 4 & Compact Heat Exchanger with Liquid Hydrogen \\
\hline 5 & Compact Heat Exchanger with Liquid Argon \\
\hline 6 & Heat Exchanger with Vacuum Orifice in Liquid Methane \\
\hline 7 & Slush Methane-LCH4 at its Triple Point with $50 \%$ Solid CH4 \\
\hline 8 & Co-current Heat Exchanger through Indirect Transfer Pipeline \\
\hline 9 & Modified X-33 RLV Propellant Densification Process with LCH4 \\
\hline 10 & Modified X-33 RLV Propellant Densification Process with R13 \\
\hline 11 & Modified X-33 RLV Propellant Densification Process with R14 \\
\hline 12 & Direct TVS Vacuum Pumping Process Scheme-On the Pad \\
\hline 13 & In-Situ Storage Vessel Densification-External Limpet Coil Heat Exchanger \\
\hline 14 & Liquid Nitrogen Pool Boiling Heat Exchanger with Recirculation Loop \\
\hline 15 & Liquid Hydrogen Pool Boiling Heat Exchanger with Recirculation Loop \\
\hline 16 & Liquid Argon Pool Boiling Heat Exchanger with Recirculation Loop \\
\hline 17 & In-Situ Storage Vessel Densification-Internal Helical Coil Heat Exchanger \\
\hline 18 & Direct Contact Cold Heat Sink \\
\hline 19 & Regenerative Hydrogen Heat Exchanger \\
\hline 20 & Closed Cycle Mechanical Vapor Compression Refrigeration-Joule-Thompson Expansion w/Nitrogen \\
\hline 21 & Closed Cycle Mechanical Vapor Compression Refrigeration-Joule-Thompson Expansion w/Argon \\
\hline 22 & Closed Cycle Mechanical Vapor Compression Refrigeration-Joule-Thompson Expansion w/Methane \\
\hline 23 & Cryocooled Prechilling in Storage Vessel \\
\hline 24 & $\dagger$ Direct TVS Vacuum Pumping Process Scheme- On Orbit \\
\hline 25 & Thermal Strap to Hydrogen Tank \\
\hline 26 & Cryocooled Prechilling of Flight Tanks \\
\hline
\end{tabular}

TABLE 3.-SOME KEY THERMOPHYSICAL PROPERTIES FOR LIQUID METHANE

\begin{tabular}{|l|ll|}
\hline \multicolumn{1}{|c|}{ Property } & \multicolumn{2}{c|}{ Methane } \\
\hline Molecular Weight & $16.042 \mathrm{~kg} / \mathrm{mol}$ & \\
Normal Boiling Point (NBP) & $111.7 \mathrm{~K}$ & $\left(201.0^{\circ} \mathrm{R}\right)$ \\
Liquid Density at NBP & $442.4 \mathrm{~kg} / \mathrm{m}^{3}$ & $\left(26.37 \mathrm{lb} / \mathrm{ft}^{3}\right)$ \\
Triple Point Temperature & $90.7 \mathrm{~K}$ & $\left(163.3{ }^{\circ} \mathrm{R}\right)$ \\
Triple Point Pressure & $11.72 \mathrm{kPa}$ & $(1.70 \mathrm{psia})$ \\
Triple Point Liquid Density & $451.7 \mathrm{~kg} / \mathrm{m}^{3}$ & $\left(28.20 \mathrm{lb} / \mathrm{ft}^{3}\right)$ \\
Solid Methane Density & $511.0 \mathrm{~kg} / \mathrm{m}^{3}$ & $\left(31.90 \mathrm{lb} / \mathrm{ft}^{3}\right)$ \\
Heat of Fusion & $60.7 \mathrm{~kJ} / \mathrm{kg}^{3}$ & $(26.10 \mathrm{Btu} / \mathrm{lb})$ \\
Heat of Vaporization & $510.1 \mathrm{~kJ} / \mathrm{kg}$ & $(219.3 \mathrm{Btu} / \mathrm{lb})$ \\
Slush Density at 50\% solids & $481.4 \mathrm{~kg} / \mathrm{m}^{3}$ & $\left(30.05 \mathrm{lb} / \mathrm{ft}^{3}\right)$ \\
Liquid Viscosity at NBP & $1.17 \times 10^{-4} \mathrm{~Pa}-\mathrm{s}$ & $\left(7.89 \times 10^{-5} \mathrm{lb} / \mathrm{ft}-\mathrm{s}\right)$ \\
Liquid Specific Heat at NBP & $3.492 \mathrm{~kJ} / \mathrm{kg}-\mathrm{K}$ & $\left(0.834 \mathrm{Btu} / \mathrm{lb}-{ }^{\circ} \mathrm{R}\right)$ \\
Liquid Thermal Conductivity at NBP & $0.188 \mathrm{~W} / \mathrm{m}-\mathrm{K}$ & $\left(0.109 \mathrm{Btu} / \mathrm{hr}-\mathrm{ft}-{ }^{\circ} \mathrm{R}\right)$ \\
J-T Coefficient., Vapor at $293 \mathrm{~K}$ & $0.00457 \mathrm{~K} / \mathrm{kPa}$ & $\left(0.0566^{\circ} \mathrm{R} / \mathrm{psi}\right)$ \\
\hline
\end{tabular}




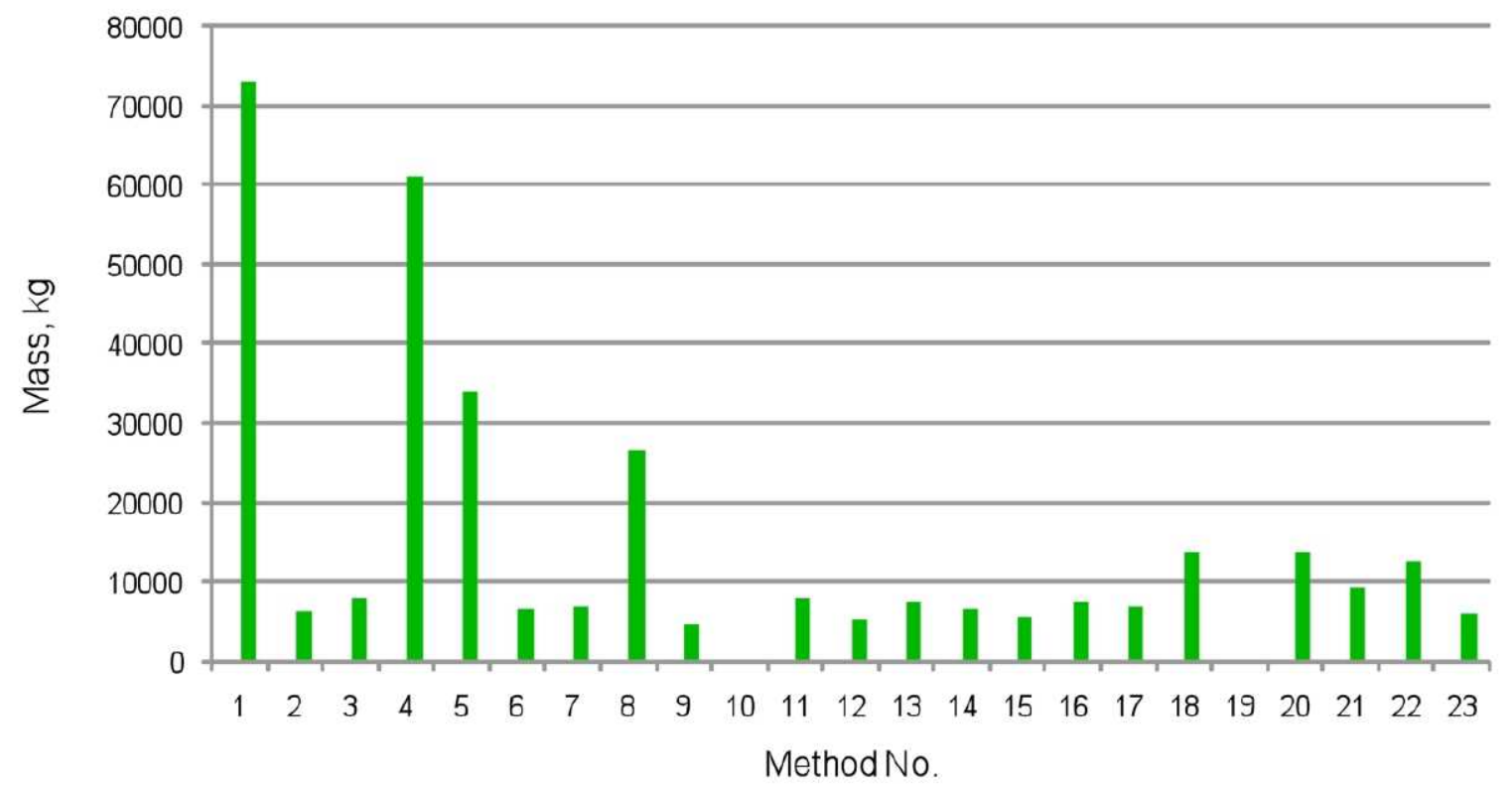

Notes: Method no. 10 is not shown because system mass exceeds $3.0 \times 10^{6} \mathrm{~kg}$. Method no. 19 system mass was not estimated during trade study.

Figure 7.-Densification system mass estimates.

\section{Densification System Mass Scaling Estimates}

The previously defined Ground Impact (GRDIMPACT) screening metric accounts for weight and area foot-print impacts of Ground Support Equipment (GSE) located on the Mobile Launch Platform (MLP). One of the many key attributes of a close-proximity MLP located propellant servicing station is minimal mass and low total area requirements. Based on the system schematics that were prepared for each concept densification method, the major equipment components required by the system were defined. Mass scaling relationships were then developed for typical cryogenic processing equipment.

The majority of the methods utilize typical cryogenic process equipment including dewars, heat exchangers, vacuum-jacket piping, vaporizers, pumps, valves, cold-gas compressors, and vacuum pumps. The mass scaling relationships allowed relatively good determination of all major component weights. These individual component weights were then tallied in order to estimate the total densification system masses. The results of this analysis for 23 of the densification methods are shown compared in Figure 7. Total conditioner system mass estimates were found to range from about 4800 to $73,000 \mathrm{~kg}$.

The following subsections of the trade study report provides a brief technical description and some discussion of each conceptual densification method that was evaluated along with its flow schematic.

\section{Methods 1 and 2: Low Temperature Gaseous Helium or Gaseous Hydrogen Bubbling}

Helium bubbling was used on the Saturn V launch vehicle to eliminate pogo effects in the oxygen feed-lines (Ref. 20). The heat load to the liquid oxygen feed-line was so great that the boiling rate caused the bubbles to merge together to form slug flow coming out of the feed-line. This created the water hammer type effects from liquid rushing into the feed-line to fill the voids left from the bubbles. The bubbles of helium effectively allowed the oxygen to evaporate into the helium bubble through diffusion, removing heat from the oxygen in the process. In 1959, Clark and Merte (Ref. 21) developed a model for bubbling heat transfer. This model was used to estimate the amounts of helium required to densify an Altair liquid methane tank as shown by the schematic in Figure 8. The 2600 liter (690 gal) liquid methane tank required to fill the Altair tanks would weigh $1700 \mathrm{~kg}$ and, in addition, carry $1000 \mathrm{~kg}$ of liquid methane at NBP. A 120,000 liter (32,000 gal) liquid helium tank would be required with a mass of 
Methods $1 \& 2$

Propellant Conditioning, Loading \&

Maintenance Loop on the MLP

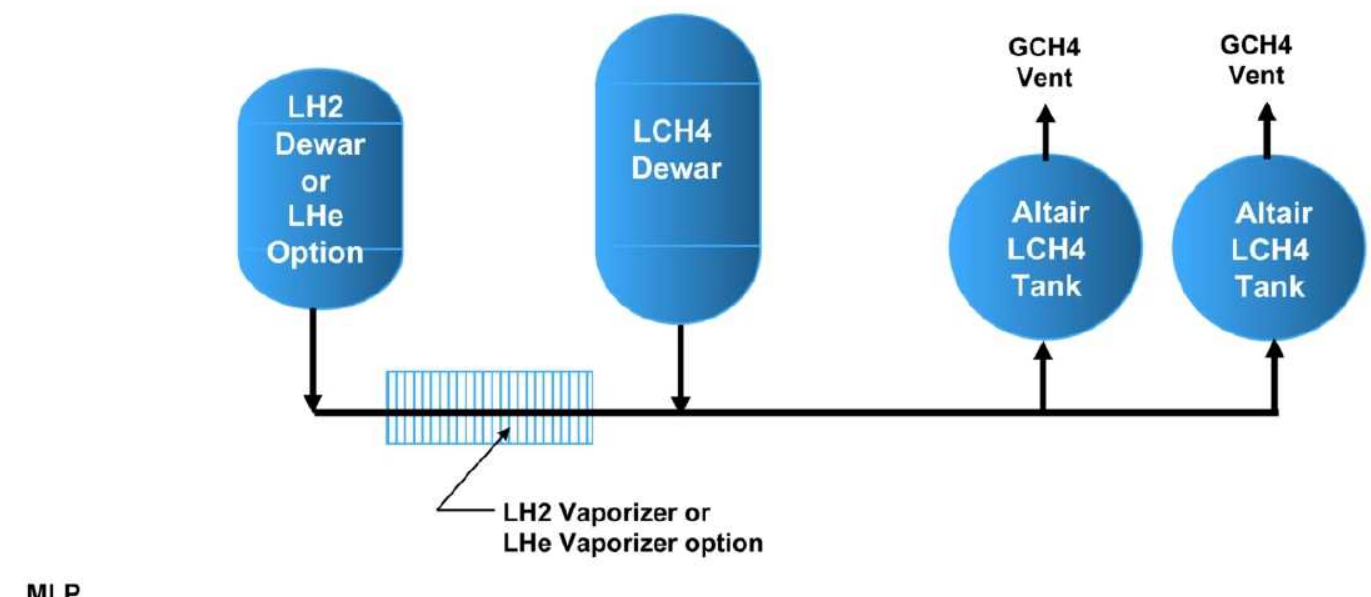

Figure 8.-Low temperature gaseous helium or hydrogen bubbling system schematic.

$55,000 \mathrm{~kg}$ carrying $15,000 \mathrm{~kg}$ of helium. Including piping and valves, the total mass of the system was estimated at $73,000 \mathrm{~kg}$. This was a much higher system weight than the majority of the other concepts evaluated, and thus the gHe bubbling method was dismissed via ranking.

Much different than Method 1, a low temperature gaseous hydrogen conditioning system (also see Figure 8) would only require a 5000 liter liquid storage capacity with a tank mass of $3000 \mathrm{~kg}$ carrying $350 \mathrm{~kg}$ of liquid hydrogen. Using the same size methane storage tank and vacuum-jacketed piping system as Method 1, the total mass of the gaseous hydrogen bubbling system was estimated at $6500 \mathrm{~kg}$. Additionally, any hydrogen that would be absorbed into the liquid methane would slightly increase the specific impulse (ISP) of the Altair ascent stage. It would also be possible to pressurize the methane tanks using this same hydrogen system, eliminating the need for helium pressurization.

\section{Method 3: Self Densification through a Transfer Pipeline TVS}

A transfer pipeline Thermodynamic Vent System (TVS) uses Joule-Thompson expansion of the propellant to cool itself. The heat exchanger is placed inside of the transfer pipeline along with a JouleThompson throttling valve at the entrance to control the expansion of the liquid. Depending on the operational mode, the exit of the heat exchanger can be vented to either the ambient atmosphere or to a vacuum pump. In this case, in order to achieve $92.5 \mathrm{~K}$ in the process fluid, a vacuum pump would be required to pump the fluid to near the triple point of methane $(\sim 91 \mathrm{~K})$ to achieve the required temperatures. These heat exchangers would be placed along the transfer line between the storage tank and the flight vessel. Once the vessel was initially filled and cooled to the proper temperature a smaller maintenance flow would be required to remove the energy that entered the tank as it sat on the pad. A schematic of the Transfer Pipeline TVS conditioner can be seen in Figure 9. Two rotary piston vacuum pumps would be needed for redundancy in the system as is used in the Heat Exchanger with Vacuum Orifice in Liquid Methane (Method 6). The same sized $6 \mathrm{~kW}$ electric, $130 \mathrm{~kg}$ gas heater would be used before the vacuum pump. The required methane storage tank would be 7600 liters (2000 gal) and weigh $4100 \mathrm{~kg}$, while containing $3200 \mathrm{~kg}$ of liquid methane. Including $250 \mathrm{~kg}$ of valves and piping, the total mass of the system is roughly $8000 \mathrm{~kg}$. 


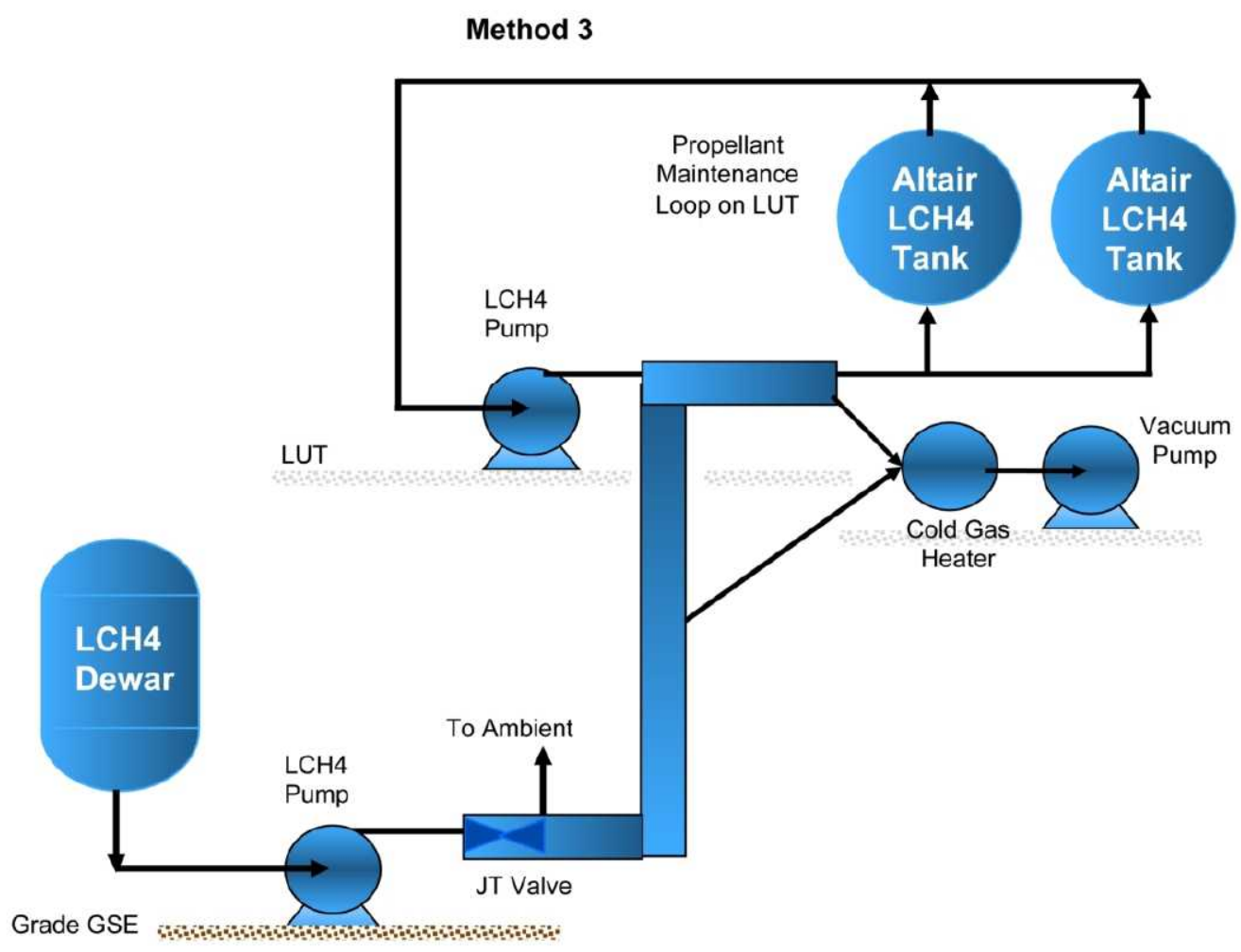

Figure 9.-Self densification through a transfer pipeline thermodynamic vent system (TVS).

\section{Methods 4 and 5: Compact Heat Exchangers with Liquid Hydrogen or Liquid Argon}

Researchers at the Kennedy Space Center have been testing a compact, expanded metallic foam heat exchanger, similar to a carbon unit tested at the University of Central Florida by Chow et al., (Ref. 22). The expanded metal foam allows for a higher heat flux through the heat exchanger, drastically reducing the size. The liquid methane could be cooled by such a heat exchanger using either liquid hydrogen or liquid argon and then pumped into the Altair tanks. A schematic of the process can be seen in Figure 10. In addition to the same 2600 liter liquid methane storage tank as required by the $\mathrm{gHe}$ or $\mathrm{gH} 2$ bubbling options, an 110,000 liter (29,000 gal) liquid hydrogen tank would be required at 50,000 kg carrying $8000 \mathrm{~kg}$ of liquid hydrogen. Similarly, a 16,500 liter liquid argon dewar would be required, with a mass of $8000 \mathrm{~kg}$. The liquid argon itself would have a mass of 23,000 kg. Both compact heat exchanger methods are excessively heavy at 61,000 for the LH2 and $34,000 \mathrm{~kg}$ for the LAr working fluids, respectively, when compared to the other densification systems analyzed.

\section{Method 6: Heat Exchanger with Vacuum Orifice in Liquid Methane}

A vacuum orifice within the liquid portion of the vehicle tank would remove the necessity of subatmospheric pressure inside the Altair tanks. Using a screen in the lower, wetted portion of the tank, it becomes feasible to remove energy from the liquid through evaporation across a restrictor screen. This could allow the removal of energy from the liquid without dropping the pressure inside the tank. A schematic of the vacuum orifice pumping process is shown in Figure 11. The required size for the vacuum pump is $0.133 \mathrm{~m}^{3} / \mathrm{s}(283 \mathrm{cfm}, 8000 \mathrm{lpm})$ and such compressors are commercial off-the-shelve. Three rotary piston vacuum pumps each at $364 \mathrm{~kg}$ would provide the necessary gas flow rates as well as lend redundancy as two pumps will provide enough flow with a third, redundant pump. In order to make up the volume of the liquid pumped, a make-up LCH4 tank is necessary. Based on the vacuum size and a 7-hr maintenance period ( $500 \mathrm{slpm})$, a 6000 liter liquid methane tank would be required. This storage tank would weigh about $3500 \mathrm{~kg}$, while the methane in the tank would be roughly $2600 \mathrm{~kg}$. Additionally, a 
small electric heater would be required to pre-heat the vent gas flow before it entered the vacuum pump and the power required for the heater would be approximately $6 \mathrm{~kW}$ at $130 \mathrm{~kg}$. The total mass of this system, including VJ lines and valves, has been estimated at $7000 \mathrm{~kg}$.

Methods $4 \& 5$
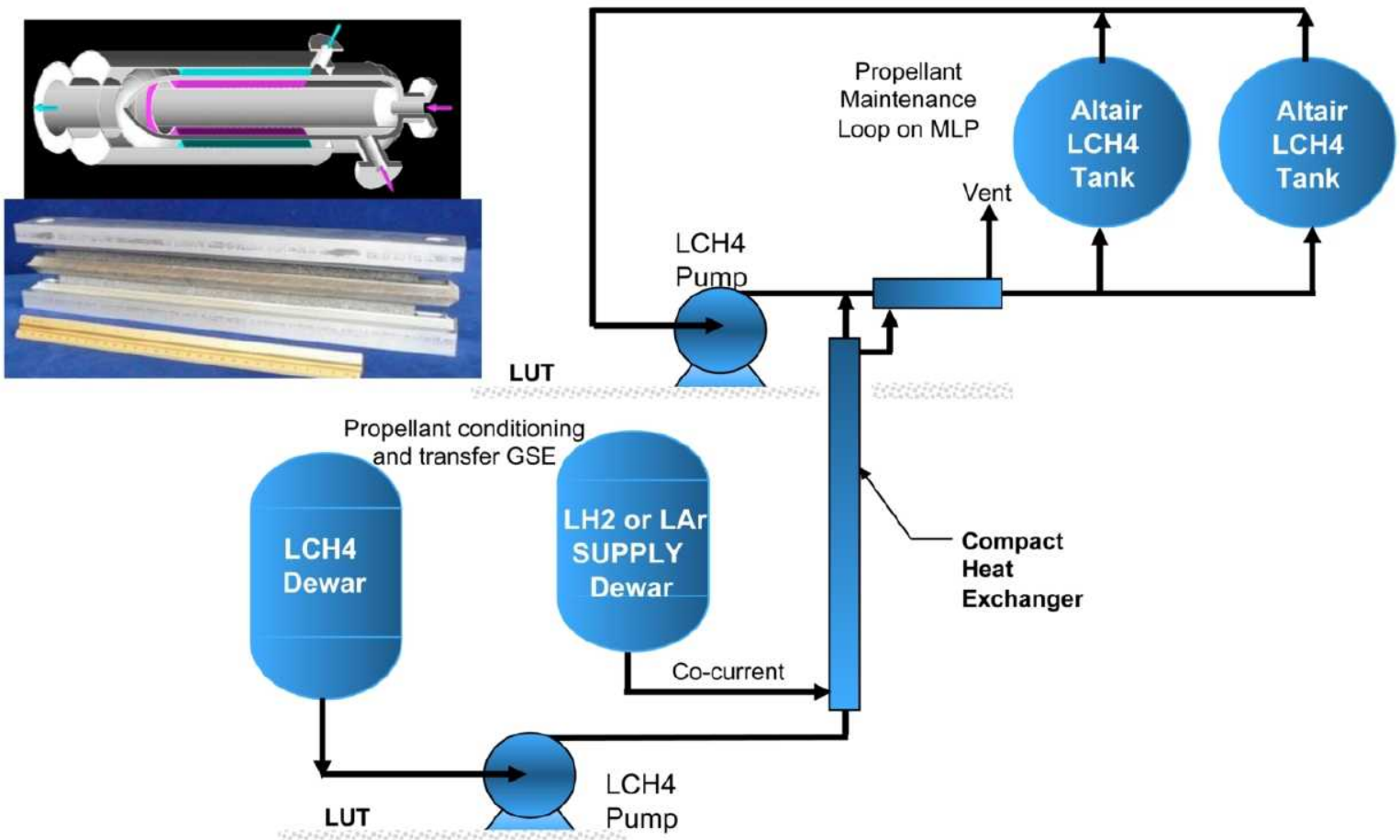

Figure 10.—Compact heat exchangers with liquid hydrogen or liquid argon.

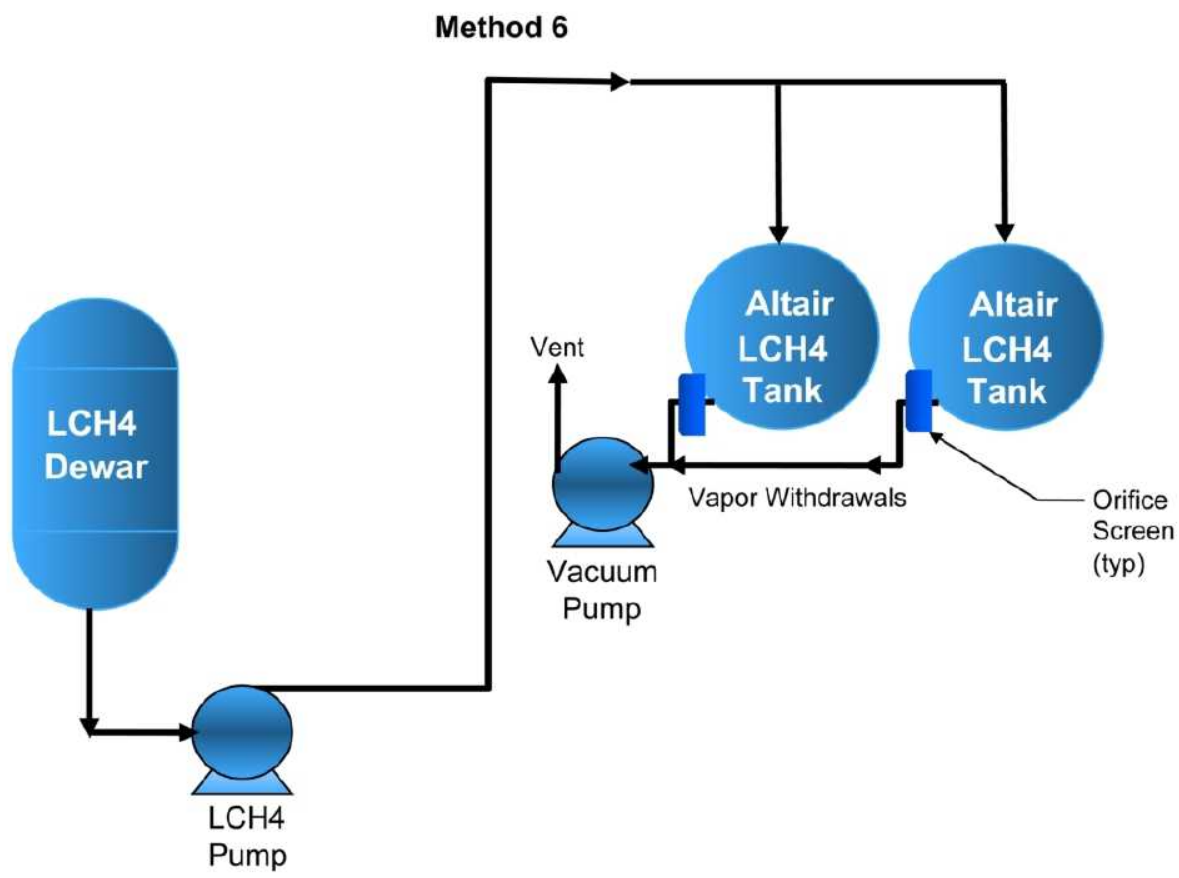

Figure 11.-Schematic of heat exchanger with vacuum orifice in liquid methane. 


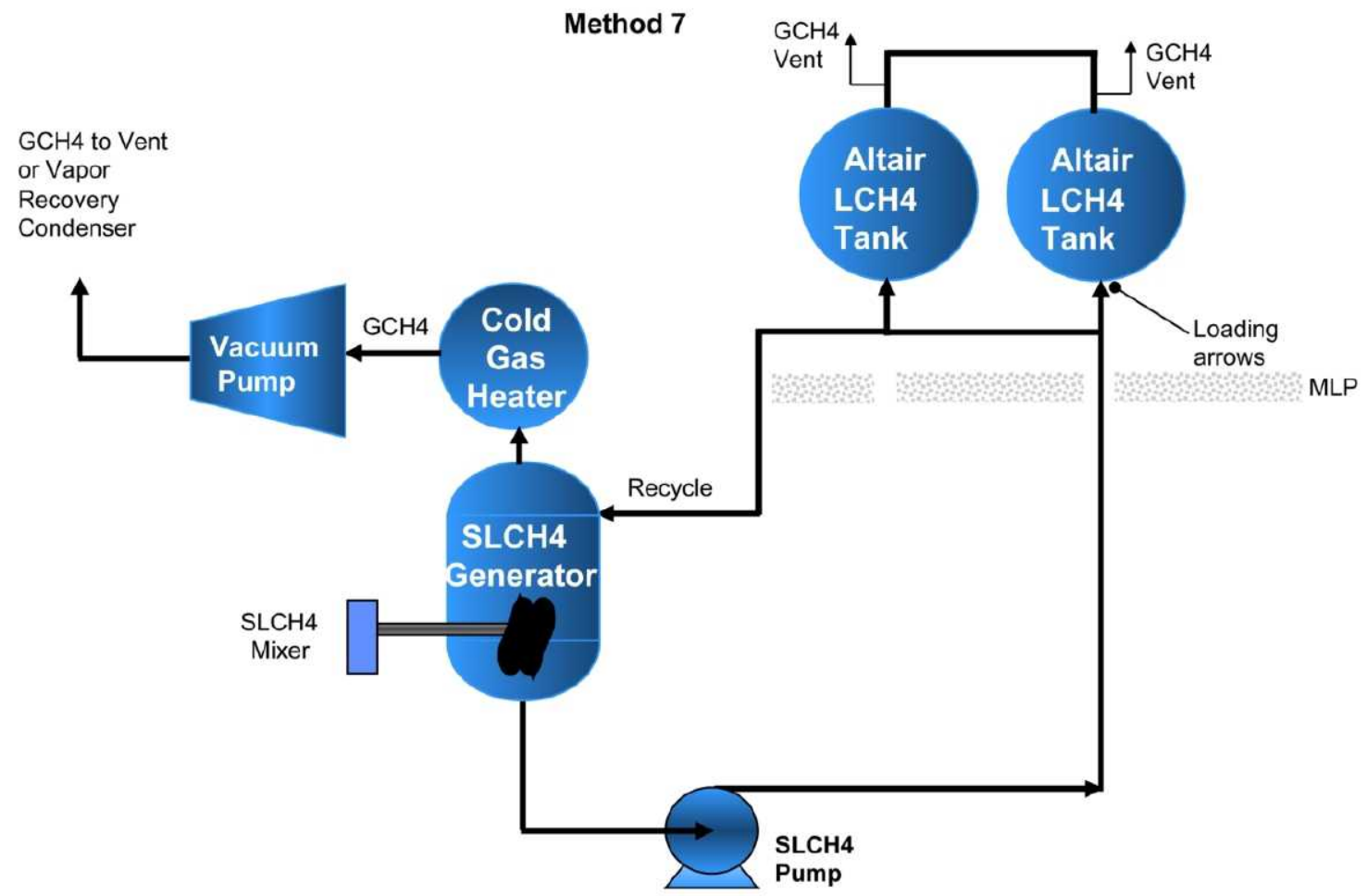

Figure 12.-Slush methane densification process schematic.

\section{Method 7: Slush Methane-LCH4 at its Triple Point with 50 Percent Solid CH4}

Slush methane, would be a 50 percent by mass solid methane with the remainder in the liquid phase at the triple point of methane $(90.8 \mathrm{~K}$ ). The use of slush methane (SLCH4) would provide enough thermal margin to allow the Altair tanks to sit for almost $24 \mathrm{hr}$ before servicing would be required to maintain the liquid temperature below $92.5 \mathrm{~K}$. Slush would be produced in a supply dewar using a vacuum pump and agitator to prevent the formation of accumulated solidified ice at the fluids' surface. During the SLCH4 production cycle, a thin layer of solid forms at the surface and then breaks-away into the bulk fluid due to the mechanical action of the agitator. After the production cycle, the slush methane would then be pumped to the Altair tanks where it would be allowed to sit until launch. A schematic of the slush methane production process is shown in Figure 12. The supply dewar would be 6000 liters and weigh $3300 \mathrm{~kg}$. The production process would start off with $2400 \mathrm{~kg}$ of NBP liquid methane. Two rotary piston vacuum pumps each rated at $510 \mathrm{~m}^{3} / \mathrm{hr}(300 \mathrm{cfm})$ would be needed for a total mass of $1400 \mathrm{~kg}$. A $54 \mathrm{~kW}$ electric heater with a mass of roughly $525 \mathrm{~kg}$ would be used to warm up the cold vapor before it enters the vacuum pump inlets. The slush agitator would be $120 \mathrm{~kg}$. Including VJ piping and valves, the total mass of the slush methane conditioner system was estimated to be around $7000 \mathrm{~kg}$.

\section{Method 8: Co-current Heat Exchanger through Indirect Transfer Pipeline}

A co-current or "parallel flow" heat exchanger would allow a triple wall pipe to be used as a heat exchanger. The inner fluid would be liquid methane while the middle fluid would be liquid nitrogen. The nitrogen would be saturated at $440 \mathrm{kPa}(49 \mathrm{psig})$ to prevent potential solidification of the liquid methane. The third or outer pipe would contain super-insulation, providing a vacuum-jacket to minimize the heat transfer to the surrounding ambient. A portion of the heat exchanger would be used in the recirculation loop for maintenance of the propellant while it's in the densified condition. Pumps would be required for 


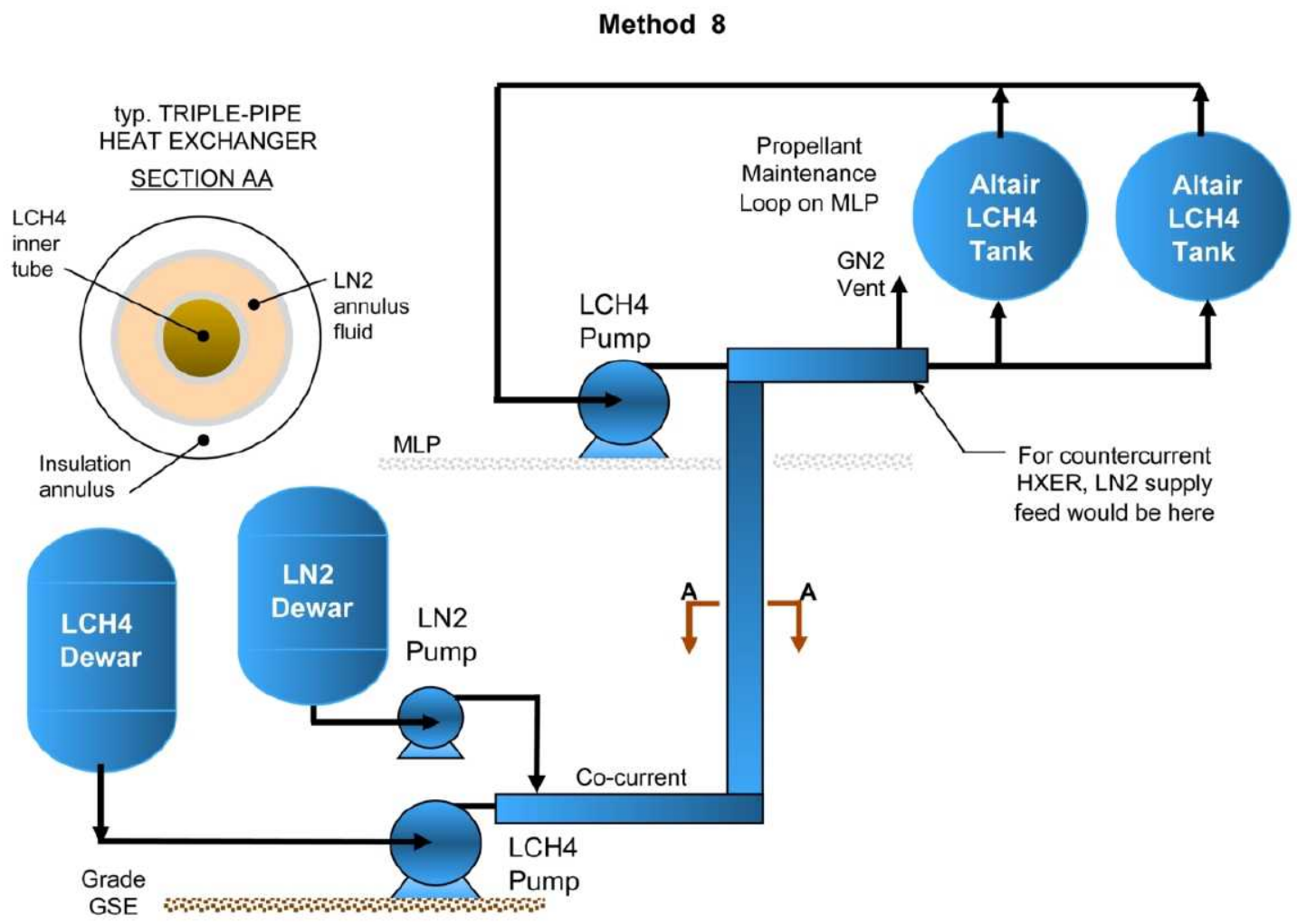

Figure 13.-Co-current heat exchanger methane densification system.

both the methane and nitrogen flows. A schematic for the co-current heat exchanger system can be seen in Figure 13. The total length of the heat exchanger would be $65 \mathrm{~m}$, meaning that it would probably be best to place the storage tanks on the ground level and pump the fluids up the side of the launch tower to the Altair tanks. Using stainless steel 316 pipe sizes of 0.75-in. Sch. 10, 1.5-in. Sch. 10, and 2.5-in. Sch. 10, the total weight of the heat exchanger would be roughly $640 \mathrm{~kg}$. Redundant pumps for each flow would total around $200 \mathrm{~kg}$. The process would require an 18,000 liter liquid nitrogen dewar of $9000 \mathrm{~kg}$ containing $14,000 \mathrm{~kg}$ of liquid. The standard 2600 liter liquid methane tank would be required, totaling $2700 \mathrm{~kg}$ of tank and fluid. With $200 \mathrm{~kg}$ of other piping and valves the total mass of the system was estimated at $27,000 \mathrm{~kg}$. However, the majority of the mass that is the two LCH4 and LN2 storage vessels would not be on the mobile launch umbilical tower (LUT). A counter current system was also considered as a conditioning method, however an additional $100 \mathrm{~m}$ long run for the LN2 supply line would be required up the side of the mobile launch platform to provide coolant to the maintenance section of the heat exchanger.

\section{Methods 9, 10 and 11: Modified X-33 RLV Propellant Densification Process with LCH4, R13 or R14 Working Fluids}

The Modified X-33 Propellant Densification Process is based on a proven thermodynamic vent system (TVS), a principle that rejects heat based on evaporation of a subcooled fluid via reduction of the "working fluids" vapor pressure. Three possible "working fluids" or refrigerants were considered in the trade study and are listed below in Table 4.

The basic process consists of a heat exchanger, a "cold-gas" compressor, and a recirculation pump. Historically, two large scale units using this particular technology were designed, built and tested during the X33 RLV program (Ref. 1) to support a future X-33 flight experiment with high-density LO2 and LH2 propellants on-board. The successful demonstrations conducted at NASA's Glenn Research Center test facilities enabled the technology to progress to a TRL rating of six. Densified methane propellant for the 
Altair would be produced by flowing normal boiling point propellant through a heat exchanger that subcools the feed. The liquid-to-liquid heat exchanger contains a bath filled with saturated LCH4 at $91.2 \mathrm{~K}$ and $12.41 \mathrm{kPa}\left(164.1^{\circ} \mathrm{R}, 1.8 \mathrm{psia}\right)$ that chills the entering methane stream to the required temperature of $92.5 \mathrm{~K}$. A multistage centrifugal compressor, that's much like a vacuum pump, is used to reject the low-pressure boil-off gas to an ambient vent, thus maintaining the sub-atmospheric pressure level in the heat exchanger bath. The contents of the Altair tanks are densified over a 1-hr time-line by recirculation of LCH4 in a closed-loop fashion from the top of Altair's propellant tanks through the modified X33 refrigeration unit and then back into the bottom. Over time, the Altair tanks become less stratified as subcooled LCH4 at the bottom fill displaces warmer LCH4 that's removed from the top withdrawal line.

TABLE 4.-POTENTIAL REFRIGERANTS FOR SUBCOOLING LCH4 BY THE MODIFIED X33 PROCESS.

\begin{tabular}{|c|l|c|c|c|}
\hline $\begin{array}{l}\text { Refrigerant } \\
\text { designation }\end{array}$ & \multicolumn{1}{|c|}{ Chemical name } & $\begin{array}{c}\text { Chemical } \\
\text { formula }\end{array}$ & $\begin{array}{c}\text { NBP, } \\
\mathrm{K}\end{array}$ & Triple point temp., K \\
\hline R50 & methane & CH4 & 111.7 & 90.7 \\
R13 & chlorotrifluoromethane & CClF3 & 191.8 & 91.7 \\
R14 & tetrafluoromethane & CF4 & 145.3 & 89.4 \\
\hline
\end{tabular}

A schematic of the LCH4 modified X33 densification process using the working fluid liquid methane is shown in Figure 14. The schematics for the R13 and R14 refrigerants are similar to the "all methane" system, with the exception of vapor recovery condensers and refrigerant storage drums that would be required downstream of the compressor, in order to recover and reuse the refrigerant fluid. For the system sizing analysis, the Altair tanks were assumed to be filled from a LCH4 bulk storage tank supply located remotely from the MLP. All three concepts would require minimal capacity methane storage dewars located on the MLP integrated with the refrigeration units in order to provide make-up fluid for the processes. The estimated system masses for the X33 densifiers using LCH4 and R14 were approximately $5000 \mathrm{~kg}$ and $8000 \mathrm{~kg}$, respectively. The spreadsheet model for the system using R13 showed that it was impractical from a performance and system mass perspective and therefore was omitted from the trade space via the normal ranking process.

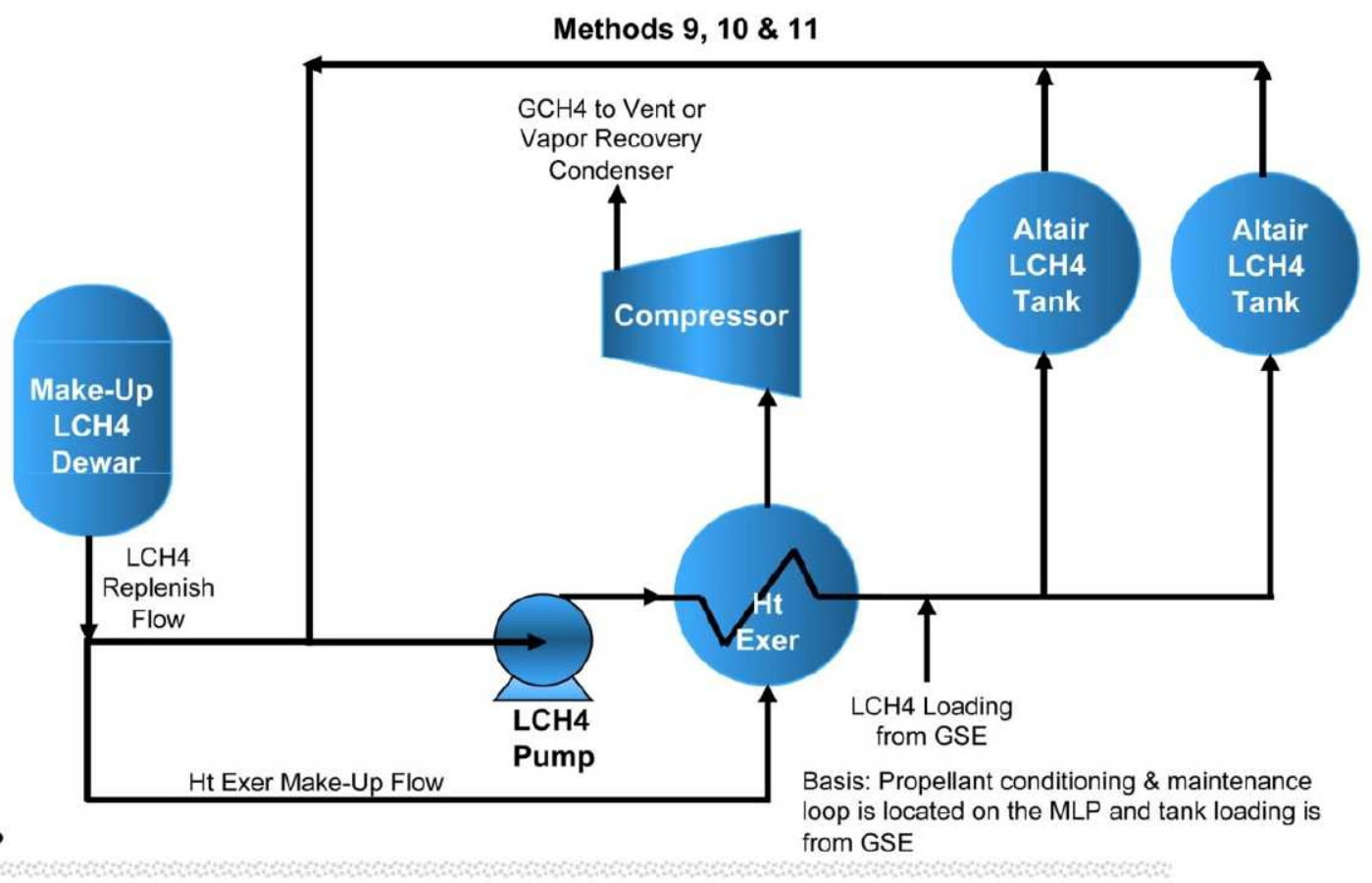

Figure 14.-Modified X-33 RLV propellant densification process with LCH4 working fluid. 


\section{Method 12: Direct TVS Vacuum Pumping Process Scheme-On the Pad}

The simplest and most direct method of conditioning the liquid methane on-the-pad would be by an evaporative cooling method that uses a vacuum pump. This particular technology has been successfully used in previous propellant conditioning test applications. These prior experiences include subcooling 13,000 gal batches of liquid hydrogen (Ref. 23) and more recently, for conditioning fully loaded tanks of NBP LCH4 for a Cryogenic Fluid Management (CFM) test conducted at the NASA Glenn Research Center (Refs. 24 and 25), a program that's also in support of Altair's cryogenic ascent stage.

The Altair tanks would be chilled and then each initially filled with $387 \mathrm{~kg}$ of NBP LCH4. The process begins by initiating a pump-down process on the ullage of the pre-loaded vehicle propellant tanks. Liquid temperature is reduced due to evaporation of LCH4 using the vacuum pumping system, while concurrently, tank ullage pressure decreases as indicated by the pump-down model results of Figure 15. The final ullage pressure needed to sub-cool LCH4 down to $92.5 \mathrm{~K}$ is $14.5 \mathrm{kPa}(2.1 \mathrm{psia})$. The analysis was based on a 1-hr conditioning time employing two rotary piston vacuum pumps each rated for a displacement of $255 \mathrm{~m}^{3} / \mathrm{hr}(150 \mathrm{cfm})$. The TVS scheme is an effective approach to subcool the fluid by direct evaporative cooling, a process that consumes about $0.14 \mathrm{~kg}$ of methane vapor boil-off to lower the temperature of $1 \mathrm{~kg}$ of NBP propellant by $19.2 \mathrm{~K}$ while maintaining a constant volume. This means that a small flow of NBP LCH4 make-up flow is added to the tanks during the pump-down. A schematic of the Direct TVS Vacuum Pumping Process is illustrated in Figure 16. The system is apparently simple to operate, has good controllability and the equipment requirements including system footprint and overall mass are relatively low in comparison to many of the other densification methods. This total mass of this system was estimated to be on the order of $5300 \mathrm{~kg}$.

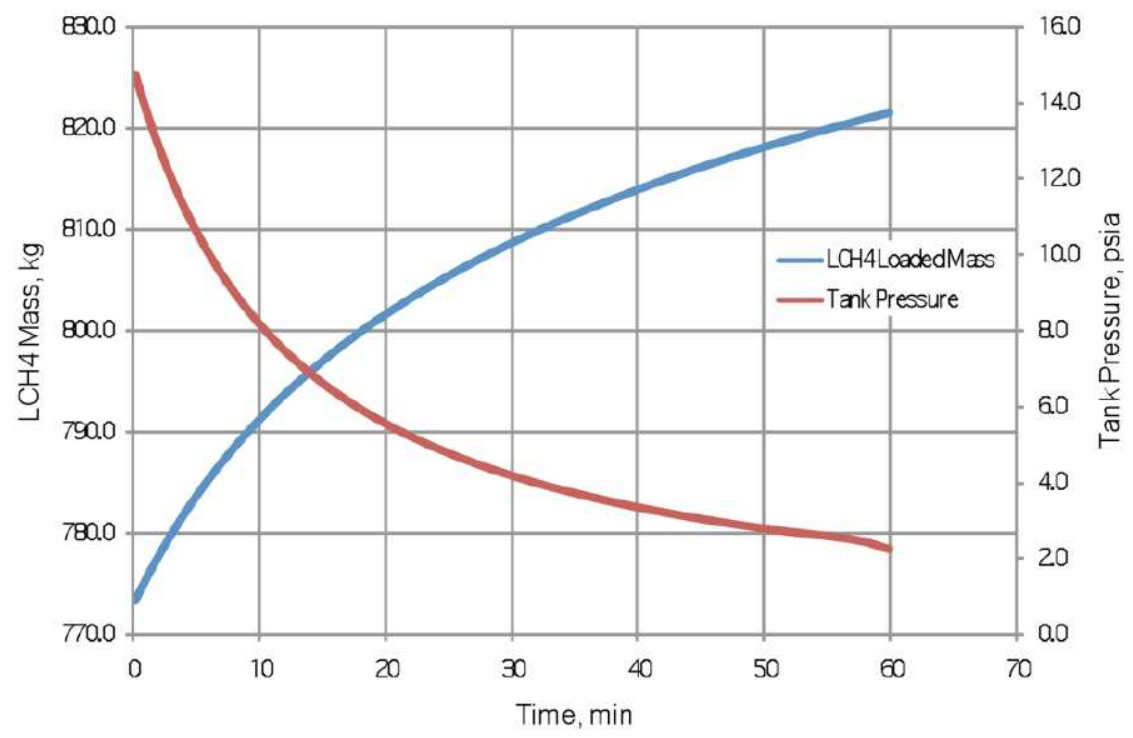

Figure 15.-Altair tank ullage pressure and total loaded mass for direct TVS pump-down. 


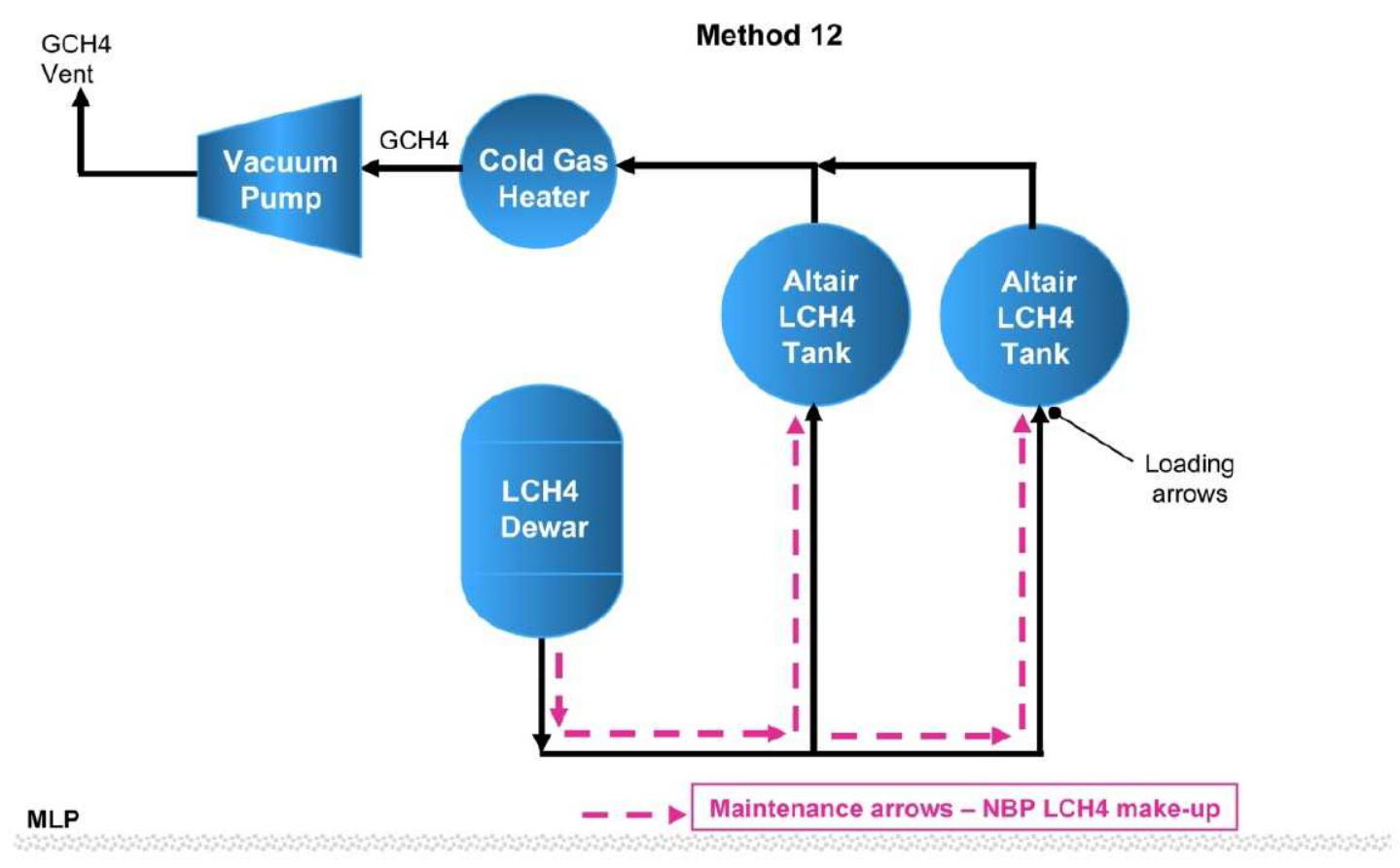

Figure 16.-Direct TVS Vacuum Pumping Process Scheme - On the Pad.

\section{Method 13: In-Situ Storage Vessel Densification-External Limpet Coil Heat Exchanger}

The in-situ or "internal" storage vessel densification process is an indirect cooling method that combines the LCH4 storage tank, sized to fully load propellant on-board both Altair tanks, with special heat exchange apparatus integrated on the vessel itself. In this case, the heat transfer apparatus is an external limpet coil, welded to the outer shell of the storage vessel wall, thus creating a full jacket. Limpet coils are basically longitudinal sections of half-pipe, typically 2- to 4-in. size, of Sch 40 stainless steel pipe. The design approach renders the system very appropriate as a modular, portable densification unit that can conceptually be temporarily positioned on the MLP and then removed shortly prior to launch. A schematic of the in-situ storage vessel densifier with limpet coil is shown in Figure 17. Liquid nitrogen is used as the cooling fluid, as LN2 is shown flowing under pressure through the limpet coil circuit and then to vent. A recirculation pump is employed in the design to move densified $\mathrm{LCH} 4$ from the densifier vessel to the Altair tanks and then back to the densifier in a closed loop fashion, thus providing either constant or intermittent propellant temperature maintenance while Ares V sits on the pad. The method is operationally flexible in that it may either be operated as a batch cooling system or a continuous process. The preliminary LCH4 conditioner vessel and LN2 storage capacities requirements were each sized at 2500 liters $(650 \mathrm{gal})$, respectively. The total estimated dry mass of the system, including margin for VJ piping and valves, was $7400 \mathrm{~kg}$. 


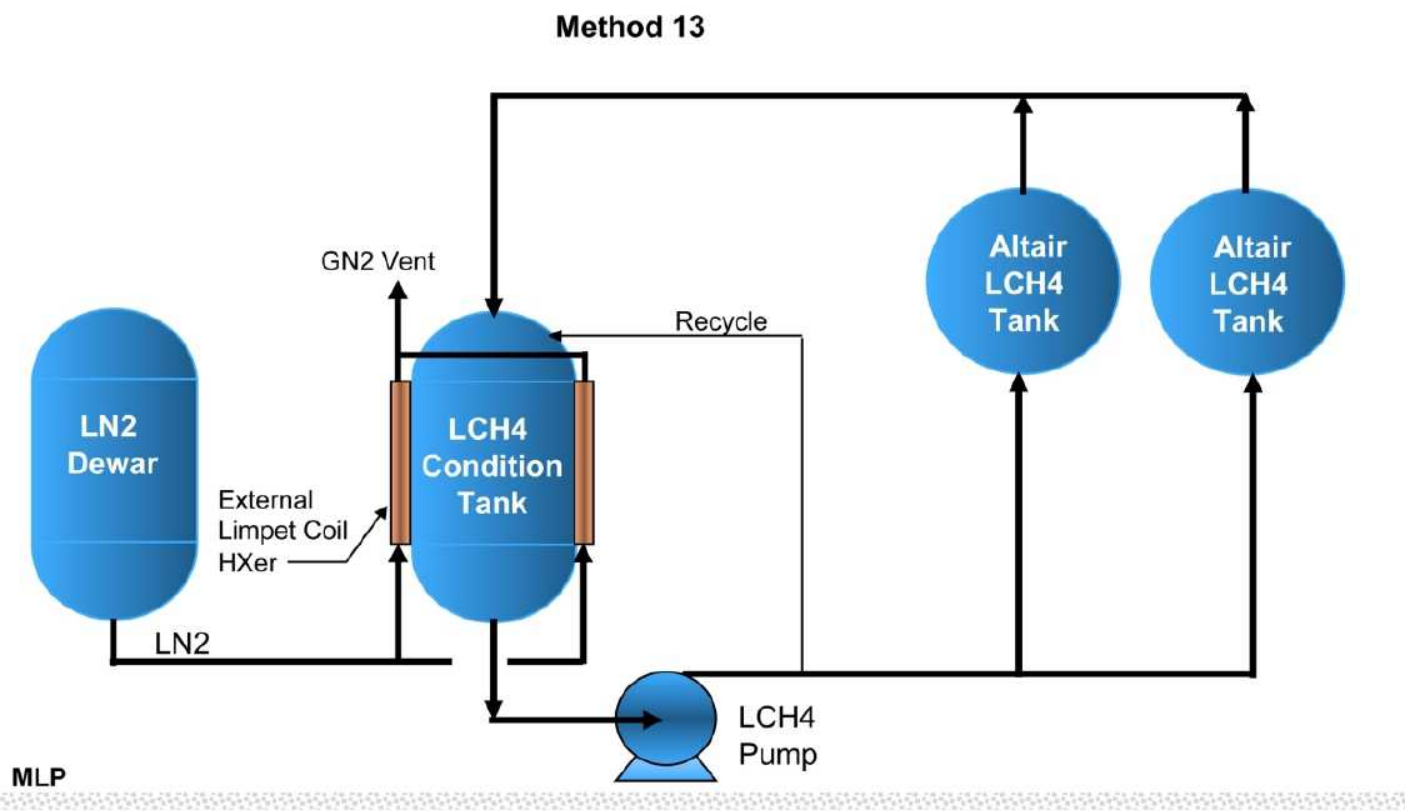

Figure 17._-In-Situ storage vessel densification - external limpet coil heat exchanger.

\section{Methods 14, 15 and 16: Liquid Nitrogen, Liquid Hydrogen or Liquid Argon Pool Boiling Heat Exchangers with Recirculation Loops}

This method uses a cryogenic liquid pool boiling heat exchanger to reduce the temperature of the methane on its way to the launch vehicle. A similar concept is being studied at KSC to deliver cold helium using a liquid hydrogen pool boiler. The recirculation loop allows for the system to absorb all of the energy that goes into the launch vehicle while sitting on the surface. This system is defined by the pool boiling heat exchanger schematic in Figure 18. Pool boiling provides high heat transfer rates at relatively easily obtainable conditions. By transferring the liquid methane through a boiling pool of liquid nitrogen, liquid argon, or liquid hydrogen, the areas of heat transfer would be much lower than in other configurations. All pool boilers would require a 2600 liter liquid methane tank that weighs $1800 \mathrm{~kg}$ for the dewar and contains $1000 \mathrm{~kg}$ of liquid methane.

A liquid nitrogen pool boiler would require a 1300 liter LN2 dewar and 1300 liter heat exchanger both with a mass of approximately $1100 \mathrm{~kg}$. A total of $1100 \mathrm{~kg}$ of liquid nitrogen would be used during the process. A pump would be needed for each liquid and would total $300 \mathrm{~kg}$ including redundant pumps. Including valves and piping, the liquid nitrogen pool boiler mass was estimated to be roughly $7000 \mathrm{~kg}$.

A liquid hydrogen pool boiler would require a 1300 liter LH2 dewar and 1300 liter heat exchanger both with a mass of approximately $1100 \mathrm{~kg}$. A total of $100 \mathrm{~kg}$ of liquid hydrogen would be used during the process. A pump would be needed for the liquid methane, but not the liquid hydrogen and would total $200 \mathrm{~kg}$ including redundant pumps. Including valves and piping, the liquid hydrogen pool boiler weight was estimated to be about $6000 \mathrm{~kg}$.

A liquid argon (LAr) pool boiler would require a 1300 liter LAr dewar and 1300 liter heat exchanger both with a mass of approximately $1100 \mathrm{~kg}$. A total of $2000 \mathrm{~kg}$ of liquid argon would be used during the process. A pump would be needed for each liquid and would total $350 \mathrm{~kg}$ including redundant pumps. Including valves and piping, the liquid argon pool boiler system mass was estimated to be approximately $7500 \mathrm{~kg}$. 


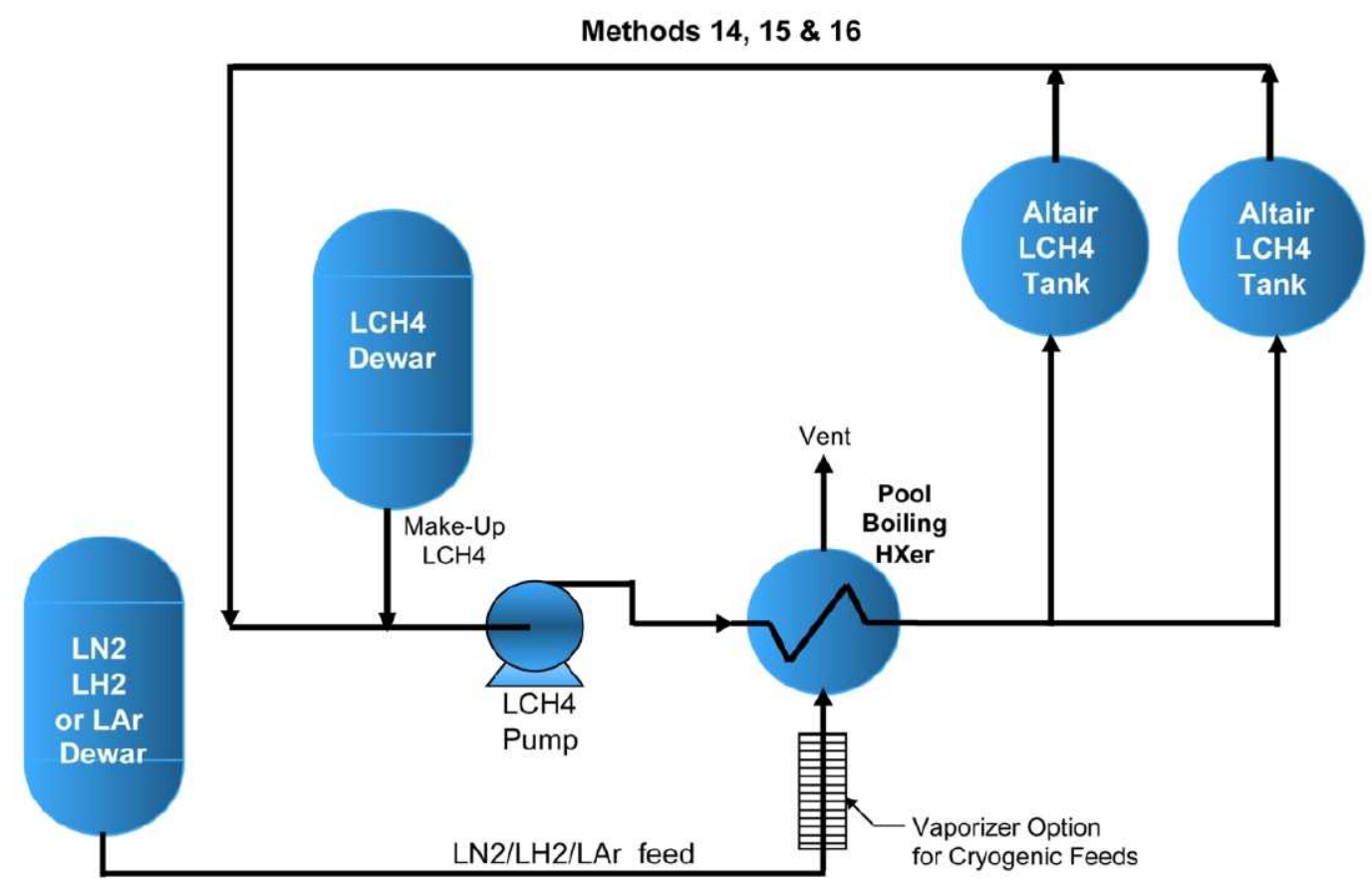

Figure 18.-Pool boiling heat exchanger with recirculation loop - LN2, LH2 or LAr.

\section{Method 17: In-Situ Storage Vessel Densification-Internal Helical Coil Heat Exchanger}

The in-situ storage vessel densification process with the internal helical coil heat exchanger is identical to the previous Method 13. The primary difference is in the design of the tank heat transfer surface area. Rather than employing the external limpet coils like Method 13, greater than five percent mass savings is realized if one uses an internal helical coil that could be constructed of $1 / 2 \mathrm{in}$. OD stainless steel tubing. This tank configuration is also more readily adaptable to a vacuum-jacket installed over the conditioning tank exterior wall. The simplified flow schematic that defines this process is given in Figure 19. The LCH4 conditioner vessel and LN2 storage capacities requirements both remain the same as Method 13, each at 2500 liters (650 gal), respectively. The total estimated dry mass of the system, including margin for VJ piping and valves, was $7000 \mathrm{~kg}$, which is about $400 \mathrm{~kg}$ less than the limpet coil approach. Finally, both processes would consume about 1900 liters (500 gal) of LN2 to support conditioner vessel chill-down, the initial LCH4 densification conditioning cycle and propellant maintenance for four consecutive launch days, which is a system requirement.

\section{Method 18: Direct Contact Cold Heat Sink}

The direct contact cold heat sink would utilize a liquid nitrogen filled heat sink. The nitrogen heat sink would take the form of a tank internal to a methane dewar. This system would rely on natural convection currents to evenly subcool the entire vessel. In order to prevent the need for a recirculation system, a gaseous helium system would be in place for pressurization of the flight tanks to return the liquid methane back to the storage dewar for reconditioning at an appropriate time. The helium would be cooled by the nitrogen vent gas to minimize the energy input into the methane upon transfer as well as to provide thermal mass to keep the tank cold. A schematic of the Direct Contact Cold Heat Sink can be seen in Figure 20. The inner nitrogen tank, would have an MAWP of 100 psig, a volume of 1300 liters and weigh $1200 \mathrm{~kg}$. The inner LN2 tank would also contain $1900 \mathrm{~kg}$ of liquid nitrogen. The methane storage tank, not including the internal nitrogen tank volume, would be 12,000 liters (3200 gal) for proper clearances and heat transfer around the inner nitrogen tank. The mass of the LCH4 dewar would be $6000 \mathrm{~kg}$ not including $3000 \mathrm{~kg}$ of liquid methane. The helium supply would require approximately $500 \mathrm{~kg}$. The total mass impact of this Direct Contact Cold Heat Sink system was estimated at 14,000 kg. 


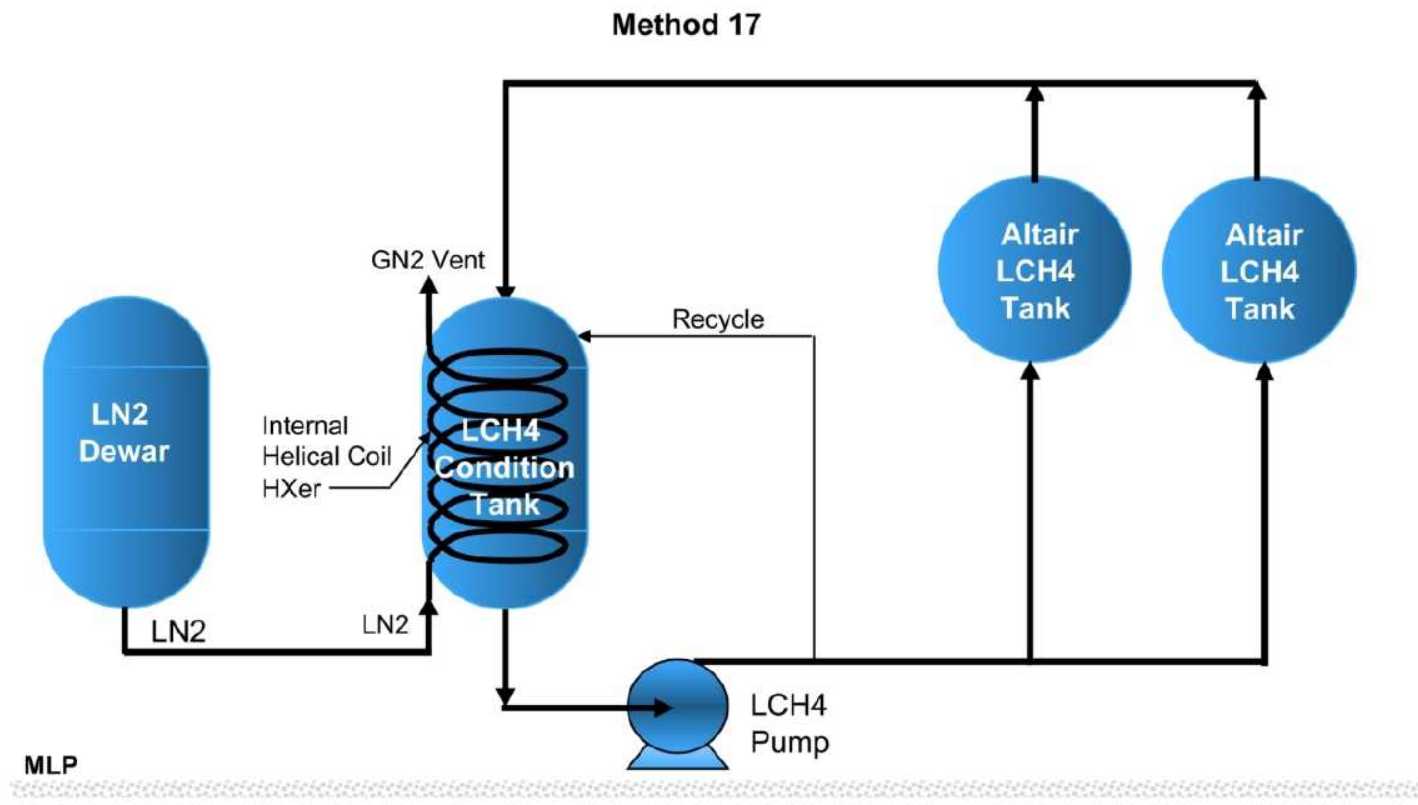

Figure 19.-In-Situ storage vessel densification - internal helical coil heat exchanger.

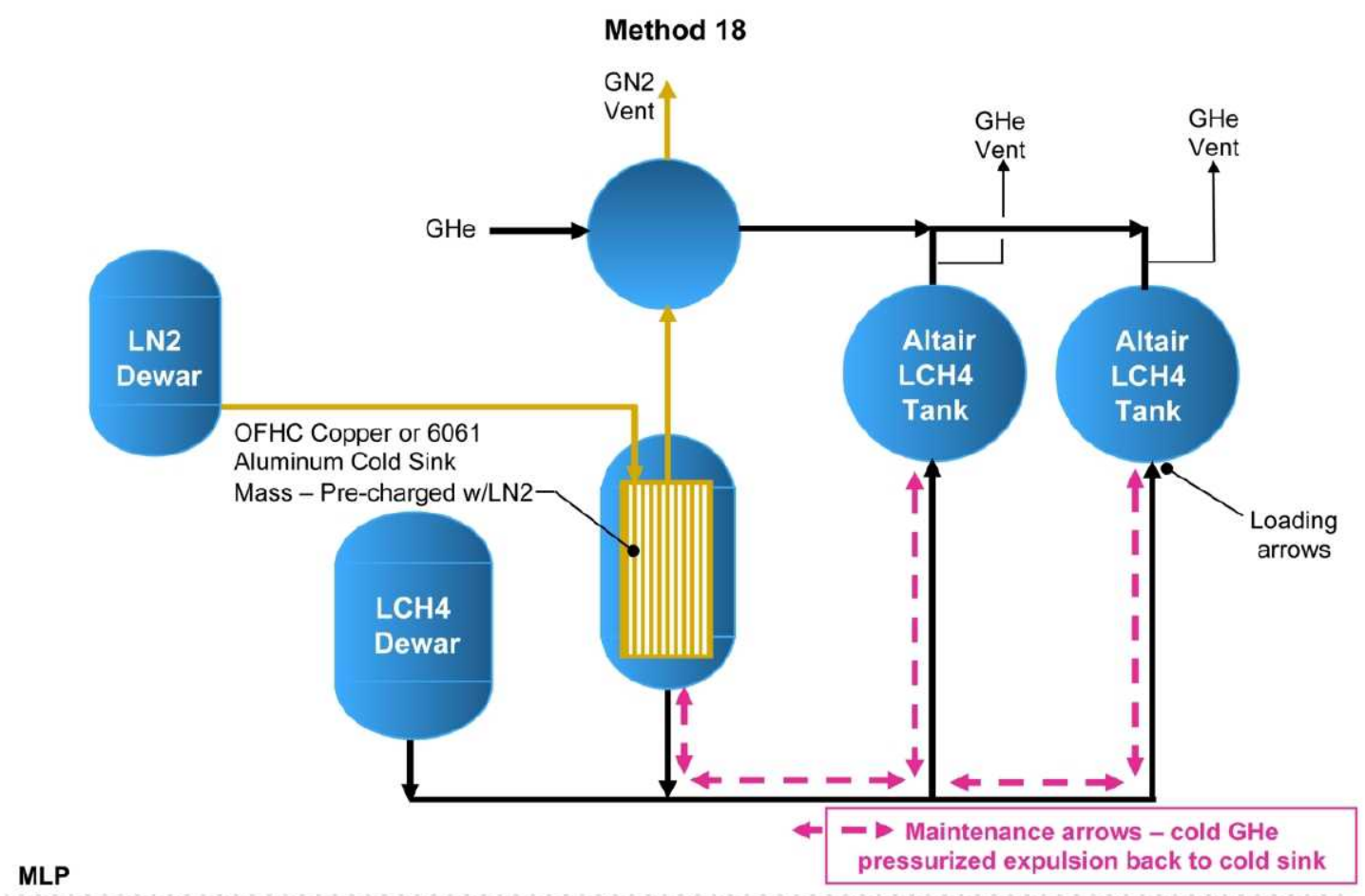

Figure 20.-Schematic for the Direct Contact Cold Heat Sink method. 


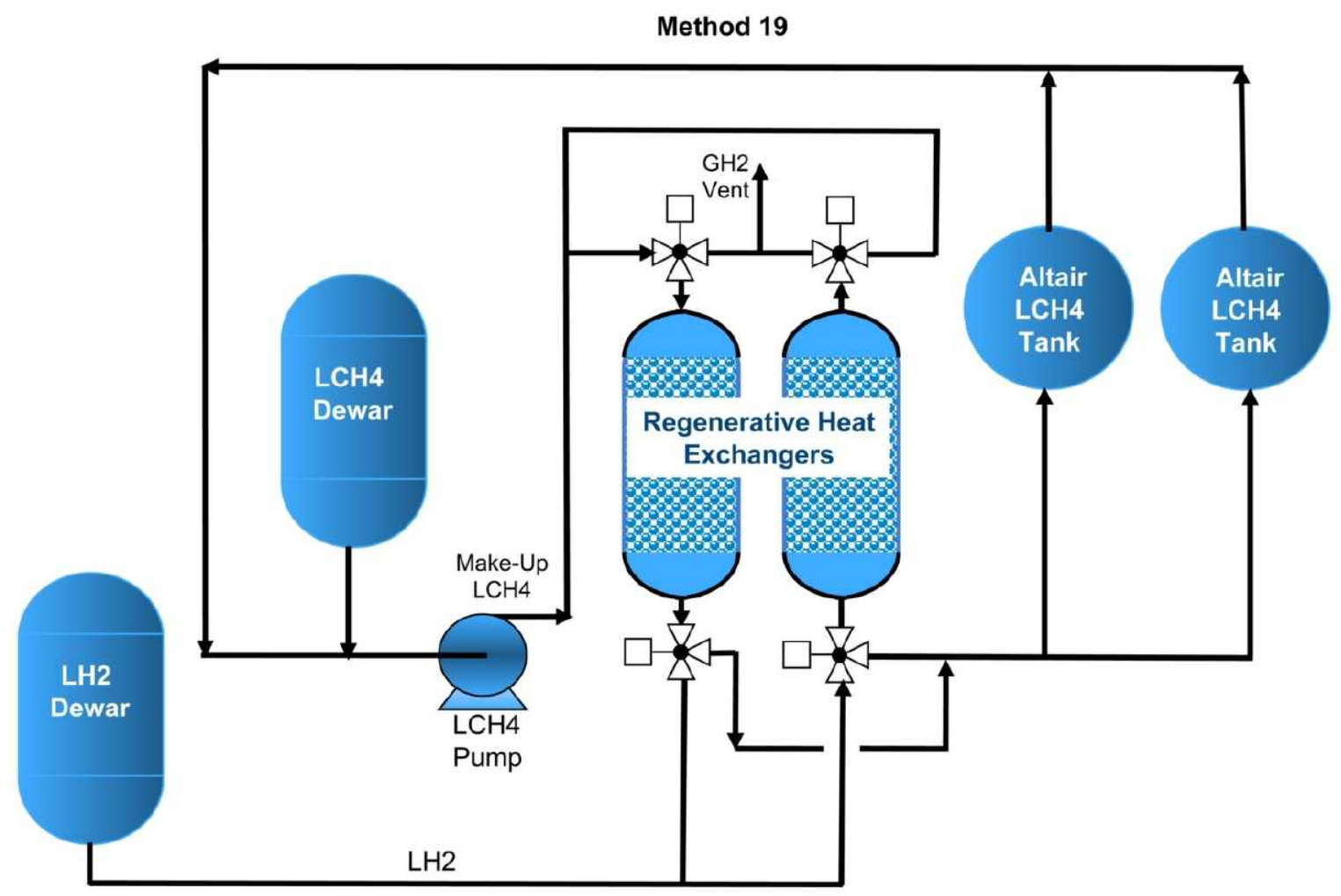

Figure 21.- Simplified flow schematic for the Regenerative Hydrogen Heat Exchanger method.

\section{Method 19: Regenerative Hydrogen Heat Exchanger}

This was the least studied methane conditioning approach, therefore, the performance and mass impacts for this method are currently uncharacterized. A concept schematic for a possible densification process using this type of heat exchanger is defined by Figure 21. The key attributes of the Regenerative Hydrogen Heat Exchanger method are the following:

- Porous finely divided metal mass ("thermodynamic sponge")

- Wires

- Spheres

- High porosity metal or metal alloys

- Alternating thermal cycles

- Accepts heat and rejects heat as the warm or cold fluid flows thru the metal media

- Cold fluid: $\mathrm{LH} 2$ at $20 \mathrm{~K}\left(36^{\circ} \mathrm{R}\right)$

- Warm fluid: $\mathrm{LCH} 4$ at $112 \mathrm{~K}\left(201^{\circ} \mathrm{R}\right)$

\section{Methods 20, 21 and 22: Closed Cycle Mechanical Vapor Compression Refrigeration-Joule- Thompson Expansion with Nitrogen, Argon or Methane}

One single-stage system using a mechanical vapor compression refrigeration cycle was considered in the trade study. Three pure refrigerants were evaluated with the spreadsheet mass/energy balance models using the common refrigeration cycle. These working fluids analyzed were nitrogen, argon and methane. The most simple subcritical refrigeration system approach for densification of LCH4 would include the following equipment: a multi-stage reciprocating compressor with interstage coolers, a high pressure discharge line, a gas cooler for the subcritical cycle where the heat of compression is rejected to cooling 


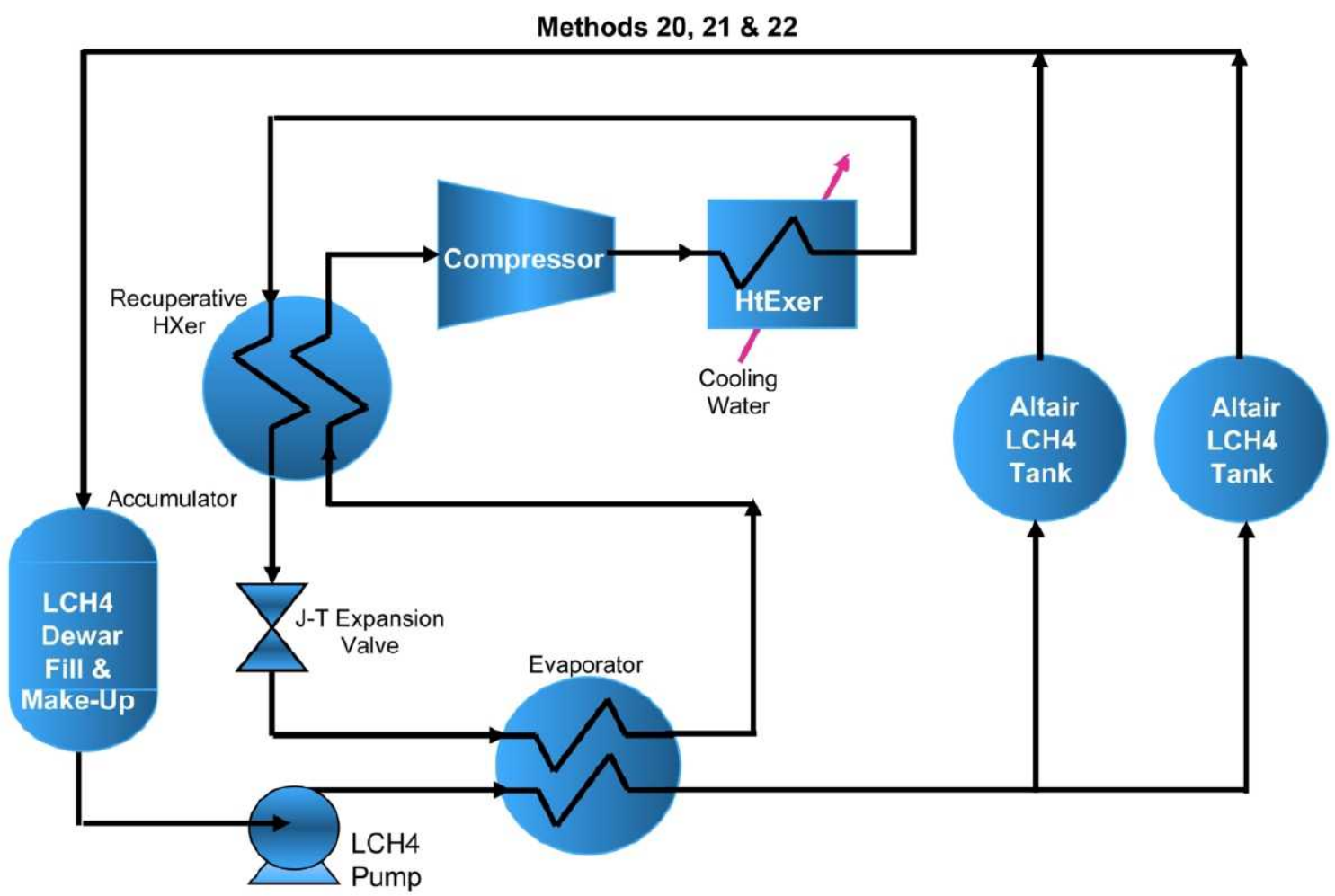

Figure 22.-Closed cycle single-stage mechanical refrigeration with Joule-Thompson expansion for LCH4 densification.

water or ambient air, a recuperative heat exchanger for pre-cooling the working fluid, an expansion device, an evaporator, a low pressure compressor suction line, and an optional liquid-line/suction-line heat exchanger that was not used.

To minimize the use of rotating turbomachinery, all concept cycles employed direct Joule-Thompson expansion valves, as opposed to turboexpanders. Expansion of the pre-cooled high pressure gas stream at $20,700 \mathrm{kPa}(3000 \mathrm{psi})$ would cause a fraction of the working fluid to liquefy. The liquefied refrigerant at $91 \mathrm{~K}\left(165^{\circ} \mathrm{R}\right)$ subcools LCH4 to the target temperature of $92.5 \mathrm{~K}$ in the evaporative heat exchanger via a recirculation process through Altair's propellant tanks. The generic mechanical refrigeration process is defined by the schematic in Figure 22. The LCH4 storage dewar in all cases contained nominally 3,800 liter (1000 gal) of liquid methane capacity. The mass impacts of these systems for each of the working fluids was driven by the compressor sizing requirements as shown by the performance numbers compared in Table 5.

TABLE 5.-MASS IMPACTS FOR THE MECHANICAL VAPOR COMPRESSION REFRIGERATION PROCESSES FOR SUBCOOLING LCH4

\begin{tabular}{|l|c|c|c|}
\hline \multicolumn{1}{|c|}{ Refrigerant } & $\begin{array}{c}\text { Compressor power } \\
(\mathrm{BHP})\end{array}$ & $\begin{array}{c}\text { Refrigerant mass flow } \\
(\mathrm{kg} / \mathrm{hr})\end{array}$ & $\begin{array}{c}\text { Total system mass } \\
(\mathrm{kg})\end{array}$ \\
\hline Nitrogen & 400 & 1820 & 13,700 \\
Argon & 350 & 1870 & 12,600 \\
Methane & 200 & 310 & 9,300 \\
\hline
\end{tabular}

\section{Method 23: Cryocooled Prechilling in Storage Vessel}

Cryocooled pre-chilling directly in the LCH4 storage vessel would entail using a cryocooler to not only produce zero-boil-off conditions, but to densify the fluid as well. This has been proposed numerous 
times by the aerospace community, but has not been thoroughly tested (Ref. 26). A small pump would be needed to allow for a circulation loop back to the storage vessel to maintain the flight vehicle fluid temperatures during maintenance. A schematic of the Cryocooled Prechilling in Storage Vessel system is shown in Figure 23. A Cryomech AL-600 Gifford McMahon cryocooler provides $600 \mathrm{~W}$ of cooling power at $80 \mathrm{~K}$. Thus four of these would be required to meet the power requirement of $2.4 \mathrm{~kW}$ plus two redundant coolers as backups for an $8 \mathrm{hr}$ chill down period. For a $24 \mathrm{hr}$ chilldown time only three cryocoolers would be required. Each coldhead has a mass of $50 \mathrm{~kg}$, so each complete system is estimated to be roughly $300 \mathrm{~kg}$ including a compressor and cold lines. A 3500 liter (900 gal) tank of liquid methane would provide the necessary liquid to allow the cryocooler to run continuously during fill and recirculation. The tank would have a mass of $3200 \mathrm{~kg}$ and contain $1500 \mathrm{~kg}$ of liquid methane. The total system mass has been estimated at $6000 \mathrm{~kg}$ for an $8 \mathrm{hr}$ chilldown of the storage tank and $5000 \mathrm{~kg}$ for a $24 \mathrm{hr}$ chilldown of the storage tank. This was the only method that was not sized for the $1 \mathrm{hr}$ conditioning time-line with-out compromising the feasibility of operation.

\section{Method 24: Direct TVS Vacuum Pumping Process Scheme-On Orbit}

In order to develop a baseline vehicle impact, it was necessary to do a quick analysis of what the impact of performing the densification using the flight vehicle hardware would be. It was determined that the easiest way to do this would be to launch enough thermal mass at the normal boiling point of liquid methane to do an on-orbit densification by a controlled opening of the vent valve to the vacuum of space. This is defined by the schematic in Figure 24. It was determined that minimally, $32 \mathrm{~kg}$ of extra propellant would be required per tank. This additional LCH4 corresponds to more or less an 8 percent increase in propellant mass onboard Altair. The tank diameter would increase by $2 \mathrm{~cm}$, with a mass increase of $1.5 \mathrm{~kg}$. That results in a 5 percent increase in dry mass not including any structural mass increase. This becomes roughly $77 \mathrm{~kg}$ of added mass to service the stage while it's in orbit. Only the dry mass would be carried to the lunar surface and back into Low Lunar Orbit (LLO) to deliver the astronauts back to the Orion crew module. The above vehicle impact analysis did not include the mass of additional propellants needed for the Ares V first stage, but that would probably be negligible in comparison to the total launch vehicles' mass at lift-off.

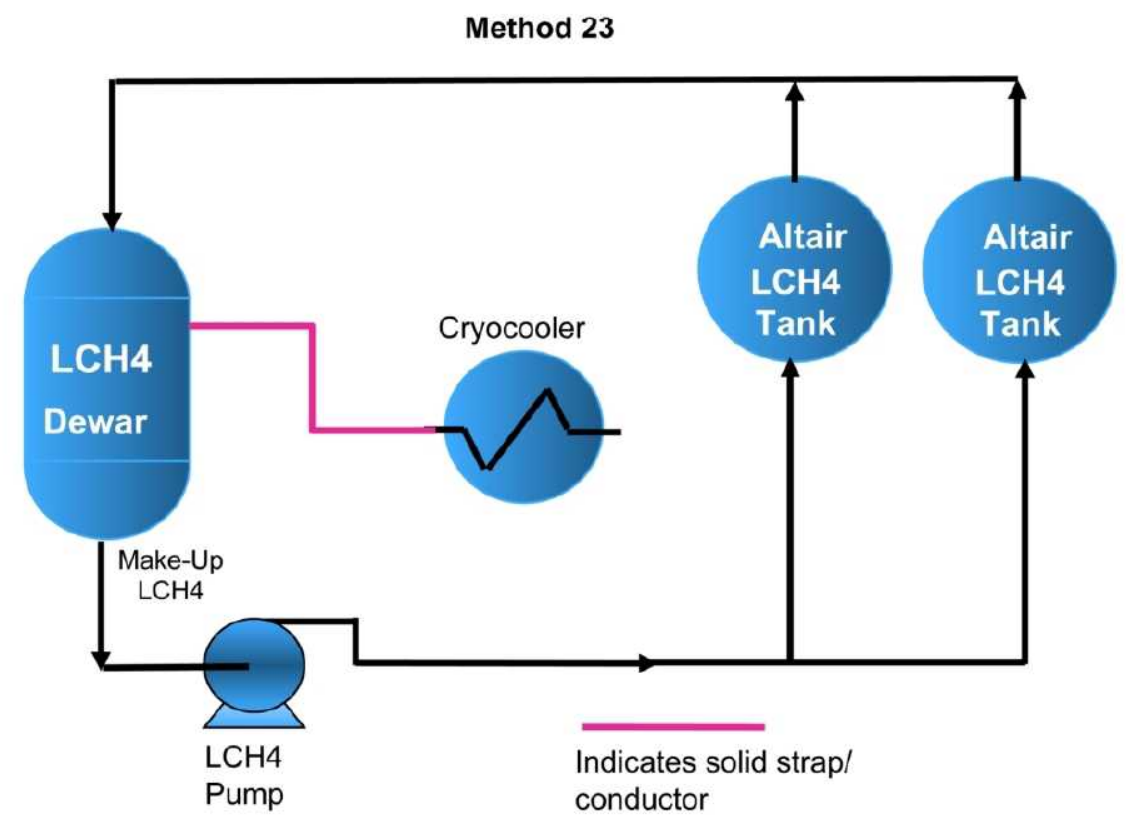

Figure 23.-Cryocooled Pre-chilling in Storage Vessel methane densification method. 


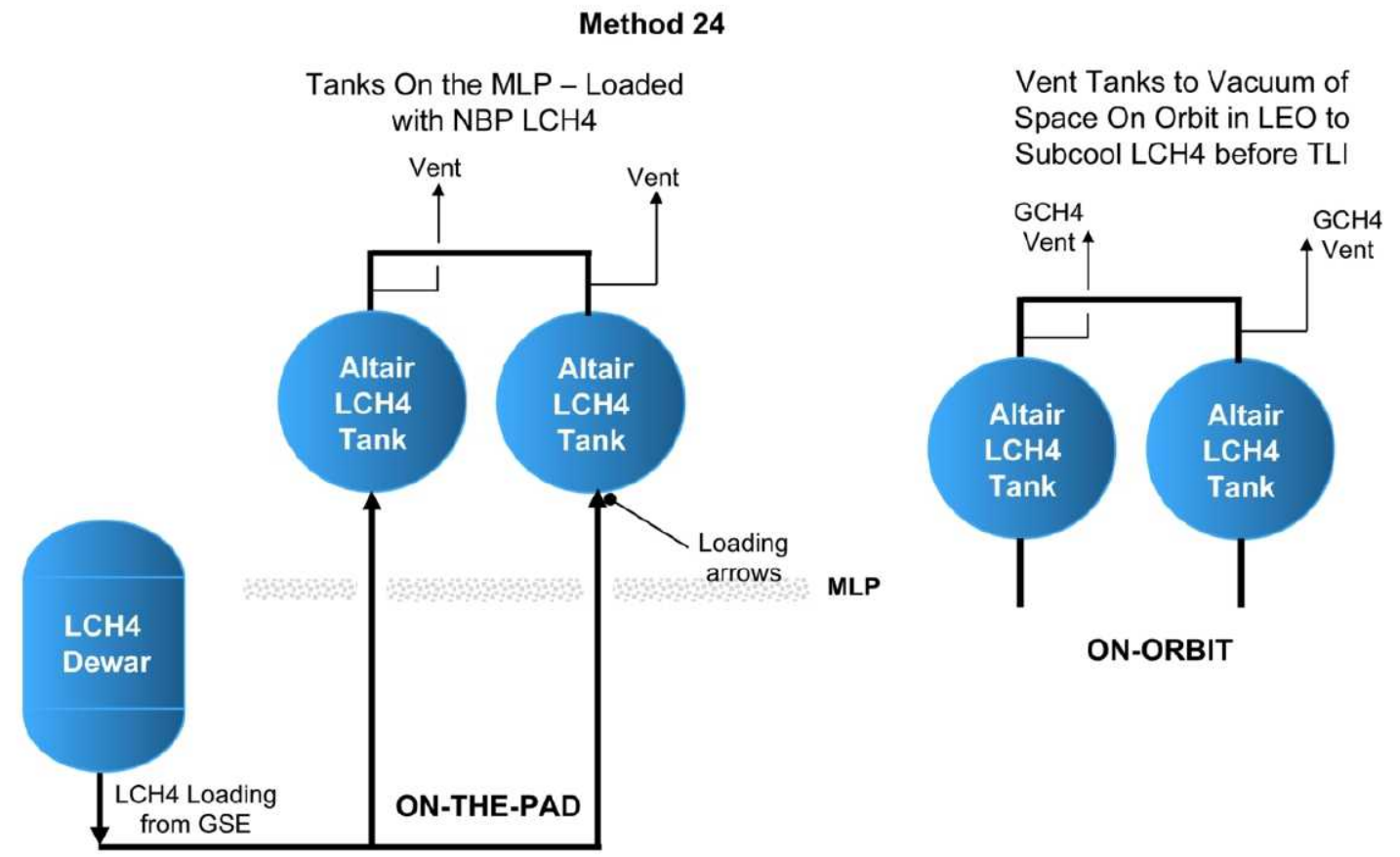

Figure 24.-System schematic for Direct TVS Vacuum Pumping - On Orbit.

\section{Method 25: Thermal Strap to Hydrogen Tank}

By thermally connecting the Altair liquid methane tanks to a liquid hydrogen tank, it was postulated that the energy removal from densification could be rejected to the hydrogen tank. A schematic of the thermal strap can be found in Figure 25. For a $1 \mathrm{hr}$ densification time, it was determined that $7.5 \mathrm{~kW}$ would be needed to achieve densification. Using a UHFC copper strap that was $0.5 \mathrm{~m}$ long, the required cross sectional area would be $0.06 \mathrm{~m}^{2}$ (a 10 - by 10 -in. block). This was deemed excessive in size, mass, and attachment area and the method was scrubbed from the trade study.

\section{Method 26: Cryocooled Pre-Chilling of Flight Tanks}

By pre-chilling the flight tanks with normal boiling point liquid hydrogen, it was thought that it might be possible to remove enough energy from the tanks to densify the liquid methane. A schematic of a prechilled flight tank can be seen in Figure 26. However, the $34 \mathrm{~kg}$ aluminum AL-2219 tanks would only provide $450 \mathrm{~kJ}$ out of the $27 \mathrm{MJ}$ required to densify the liquid methane. A cryocooler attached directly to the flight tanks was discussed as well under this concept, but a ground based cooler would suffer from the same issues as previously discussed with the Thermal Strap method. Thus the cryocooler pre-chilling of the flight tanks was abandoned as an unfeasible solution. 


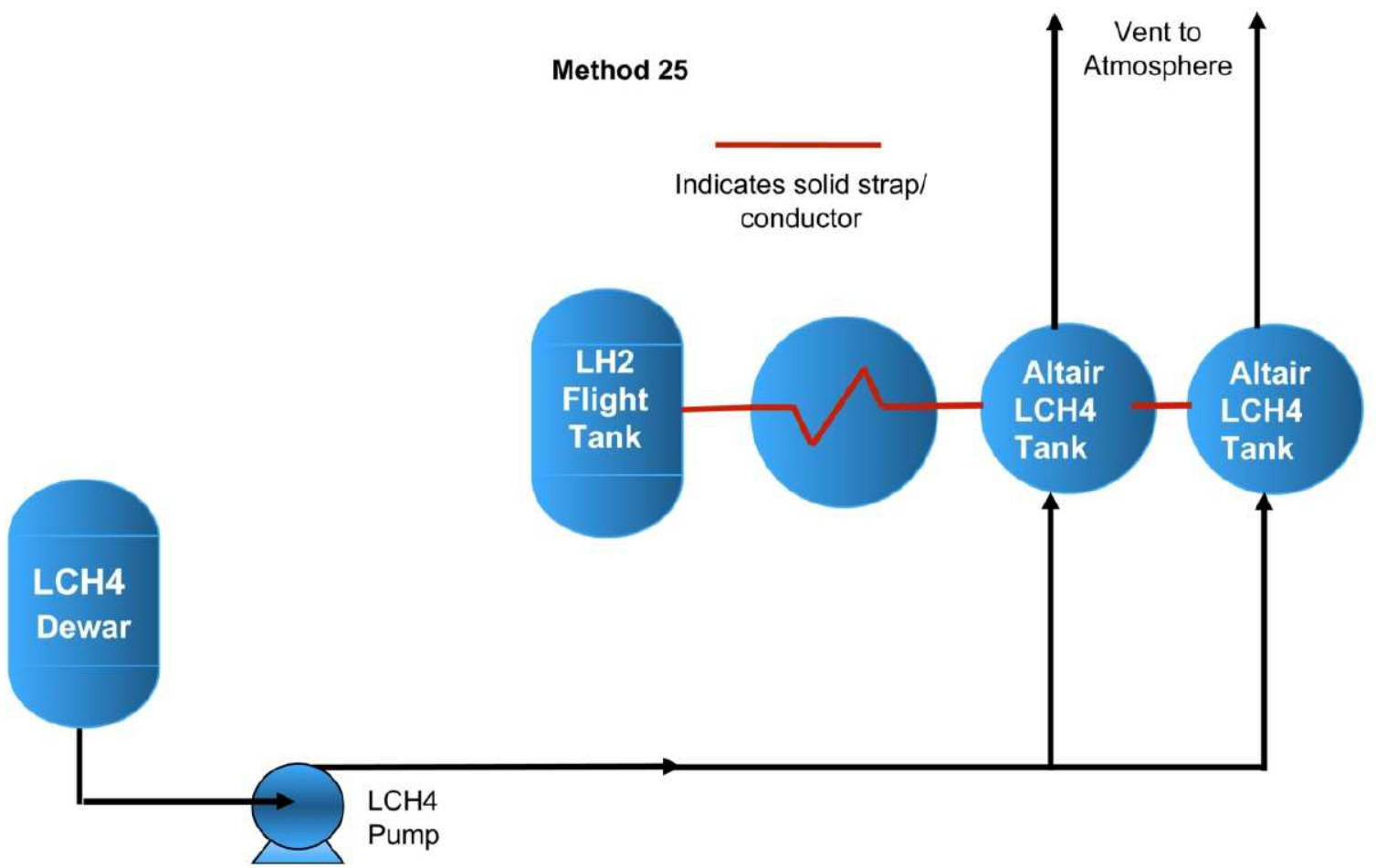

Figure 25.-Thermal Strap to Hydrogen Tank conditioning method.

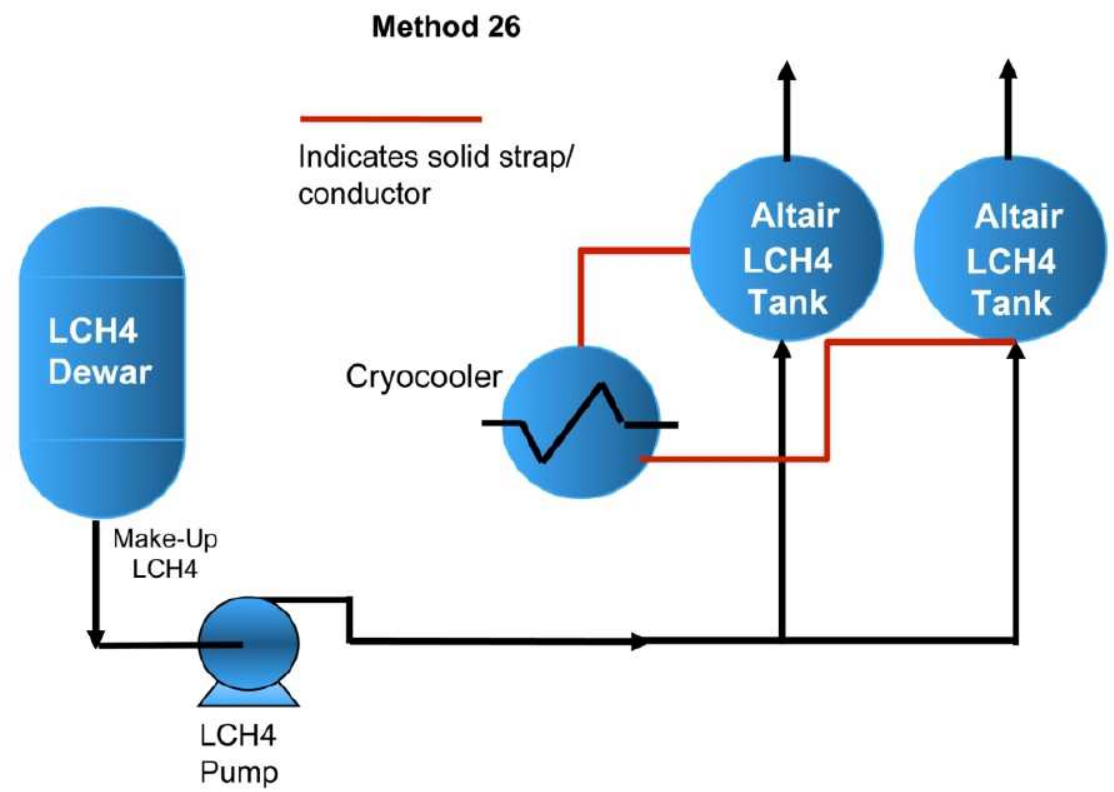

Figure 26._System schematic for Cryocooled Pre-chilling of Flight Tanks. 


\section{Technical Note on Pump Reliability}

It is often pursued by launch pad designers to minimize the amount of rotating machinery on the launch pad. The main reason given for this practice is the reliability issues of the machinery. An effort was made during the study to gather all of the historical information from the existing rotating machinery on the pads. The Space Shuttle liquid oxygen pumps have required corrective action 14 times in 214 loading attempts. Not one of the 14 times has the second pump failed thus causing a scrub. The reliability for an individual LOX pump was calculated to be 93.4 percent. The reliability of two pumps each having a 93.4 percent reliability is 99.6 percent. The reliability of two pumps is estimated to be sufficiently high enough to permit the use of liquid transfer pumps as required for the methane densification systems. For three pumps at 93.4 percent reliability, the probability of two pumps failing is less than 2.5 percent.

\section{Phase I Method Screening Results}

After the densified methane delivery methods were technically evaluated both operationally and for performance, a down select screening analysis was made using a Kepner-Tregoe trade matrix (Ref. 27). The average scores (X) of all the methods for each of the seven metrics were calculated based on the individual scores generated by five technical reviewers. The average scoring data for the various metrics are reported in Table 6 while the scale range that was used is described below.

- Scale Range: 1 to 10

- Highest Score: 10 (most desirable)

- Scale Definitions

- 10: minimal impact/cost, optimal performance

- 7: minor impact/cost, acceptable performance

- 4: major impact/cost, marginal performance

- 1: extreme impact/cost, failed performance with slim possibility of improvement

- 0 : unacceptable, all zeros will be thrown out of trade space

The rankings of each system were then compiled into a ranking spreadsheet where the weight of each individual metric was a variable. The term used for the weighting variables were referred to as Importance Factors $(\lambda)$ for each of the seven metrics. Using a variety of different weighting scenarios that ranged from each $\lambda$ being equally weighted $(\lambda=1 / 7)$ to COST and TRL $\lambda$ 's being omitted $\left(\lambda_{C}=0.0\right.$ and $\lambda_{\mathrm{T}}=0.0$ ) with a higher emphasis on the SAFETY metric, the dependence of the weighting factors became minimized. There were five Importance Factor distributions that were run in the screening analysis as shown by the values applied in Table 7. The following expression provides the mathematical relation for computing the total score $(\Phi)$ for each methane conditioner method based on their average scores $(\mathrm{X})$ plus factoring in the different values of $\lambda$.

$$
\Phi=\mathrm{X}_{\mathrm{S}} \cdot \lambda_{\mathrm{S}}+\mathrm{X}_{\mathrm{F}} \cdot \lambda_{\mathrm{F}}+\mathrm{X}_{\mathrm{G}} \cdot \lambda_{\mathrm{G}}+\mathrm{X}_{\mathrm{D}} \cdot \lambda_{\mathrm{D}}+\mathrm{X}_{\mathrm{C}} \cdot \lambda_{\mathrm{C}}+\mathrm{X}_{\mathrm{T}} \cdot \lambda_{\mathrm{T}}+\mathrm{X}_{\mathrm{O}} \cdot \lambda_{\mathrm{O}}
$$

where,

$\Phi=$ total method score

$\mathrm{X}=$ average metric score

$\lambda=$ importance factor for metric

subscripts for metrics

$\mathrm{S}=$ SAFETY

$\mathrm{F}=$ FLTIMPACT

$\mathrm{G}=$ GRDIMPACT

$\mathrm{D}=$ DENSPERF 


$$
\begin{aligned}
& \mathrm{C}=\text { COST } \\
& \mathrm{T}=\text { TRL } \\
& \mathrm{O}=\text { OPFLEX }
\end{aligned}
$$

\begin{tabular}{|c|c|c|c|c|c|c|c|c|}
\hline \multicolumn{2}{|r|}{ CONCEPT } & $\begin{array}{c}\text { SAFETY } \\
\text { Xs }\end{array}$ & $\begin{array}{c}\text { FLTIMPACT } \\
\mathrm{X}_{\mathrm{F}}\end{array}$ & $\begin{array}{c}\text { GRDIMPACT } \\
\mathrm{X}_{\mathrm{G}}\end{array}$ & $\begin{array}{c}\text { DENSPERF } \\
\mathrm{X}_{\mathrm{D}}\end{array}$ & $\begin{array}{c}\cos T \\
\mathrm{X}_{\mathrm{C}}\end{array}$ & $\begin{array}{l}\text { TRL } \\
\mathrm{X}_{\mathrm{T}}\end{array}$ & $\begin{array}{c}\text { OPFLEX } \\
\mathrm{X}_{\mathrm{O}}\end{array}$ \\
\hline 1 & Helium Bubbling & 7.80 & 6.80 & 4.20 & 6.00 & 4.50 & 6.50 & 6.00 \\
\hline 2 & Hydrogen Bubbling & 5.40 & 8.60 & 7.80 & 7.20 & 6.88 & 3.00 & 6.00 \\
\hline 3 & Line TVS & 5.60 & 7.90 & 5.80 & 6.60 & 5.75 & 4.00 & 6.50 \\
\hline 4 & Compact H/E - H2 & 5.30 & 7.80 & 5.20 & 6.80 & 6.00 & 4.50 & 6.75 \\
\hline 5 & Compact H/E- Ar & 7.70 & 7.80 & 5.20 & 7.40 & 5.00 & 4.50 & 6.00 \\
\hline 6 & Vacuum Orifice & 6.50 & 6.90 & 7.80 & 6.20 & 7.50 & 4.00 & 6.75 \\
\hline 7 & Slush Methane & 5.80 & 7.90 & 7.60 & 8.10 & 6.33 & 6.00 & 7.63 \\
\hline 8 & Co-current H/E & 7.40 & 8.10 & 5.00 & 7.50 & 5.67 & 7.50 & 6.75 \\
\hline 9 & Modified X-33, LCH4 & 6.50 & 7.80 & 8.40 & 7.40 & 6.75 & 7.00 & 8.00 \\
\hline 10 & Modified X-33, R13 & 4.00 & 7.80 & 3.00 & 4.60 & 5.00 & 4.00 & 6.75 \\
\hline 11 & Modified X-33, R14 & 4.00 & 7.80 & 5.60 & 6.80 & 5.67 & 5.00 & 6.75 \\
\hline 12 & Direct TVS & 6.10 & 7.20 & 8.40 & 7.80 & 7.67 & 7.50 & 7.00 \\
\hline 13 & In-SITU Limpet & 7.50 & 7.40 & 5.80 & 6.80 & 7.00 & 7.00 & 6.75 \\
\hline 14 & LN2 H/E & 7.10 & 7.80 & 5.80 & 6.90 & 5.75 & 4.50 & 6.75 \\
\hline 15 & LH2 H/E & 5.20 & 7.70 & 7.00 & 6.90 & 5.75 & 4.50 & 6.13 \\
\hline 16 & $\mathrm{LAr} \mathrm{H/E}$ & 7.00 & 7.80 & 5.30 & 6.80 & 5.38 & 4.50 & 7.00 \\
\hline 17 & In-SITU Coil & 7.20 & 7.20 & 6.40 & 7.50 & 7.00 & 5.50 & 7.06 \\
\hline 18 & Direct Contact Cold Heat Sink & 7.20 & 6.80 & 5.50 & 6.20 & 7.50 & 5.50 & 5.50 \\
\hline 19 & Regenerative $\mathrm{H} 2 \mathrm{H} / \mathrm{E}$ & 4.00 & 6.00 & 4.00 & 4.33 & 0.00 & 3.50 & 3.67 \\
\hline 20 & Closed Cycle Refrig. JT - N2 & 5.75 & 7.25 & 4.25 & 7.00 & 3.50 & 4.00 & 6.33 \\
\hline 21 & Closed Cycle Refrig. JT - Ar & 5.50 & 7.50 & 4.50 & 7.00 & 3.50 & 4.00 & 6.00 \\
\hline 22 & Closed Cycle Refrig. JT - $\mathrm{CH} 4$ & 5.00 & 7.25 & 4.00 & 6.75 & 3.50 & 4.00 & 5.33 \\
\hline 23 & Cryocooler & 8.50 & 7.00 & 9.00 & 6.50 & 5.00 & 4.50 & 5.50 \\
\hline
\end{tabular}

TABLE 6.-AVERAGED SCORE DATA FOR SCREENING METRICS OF THE LCH4 CONDITIONER METHODS.

TABLE 7.-IMPORTANCE FACTOR DISTRIBUTIONS

\begin{tabular}{|c|c|c|c|c|c|c|c|c|}
\hline $\begin{array}{c}\text { Importance } \\
\text { factor } \\
\text { distribution }\end{array}$ & $\begin{array}{c}\text { SAFETY } \\
\lambda_{\mathrm{s}}\end{array}$ & $\begin{array}{c}\text { FLTIMPACT } \\
\lambda_{\mathrm{F}}\end{array}$ & $\begin{array}{c}\text { GRDIMPACT } \\
\lambda_{\mathrm{G}}\end{array}$ & $\begin{array}{c}\text { DENSPERF } \\
\lambda_{\mathrm{D}}\end{array}$ & $\begin{array}{c}\text { COST } \\
\lambda_{\mathrm{C}}\end{array}$ & $\begin{array}{c}\text { TRL } \\
\lambda_{\mathrm{T}}\end{array}$ & $\begin{array}{c}\text { OPFLEX } \\
\lambda_{\mathrm{O}}\end{array}$ & $\begin{array}{c}\text { Sum } \\
\text { of the } \lambda\end{array}$ \\
\hline 1 & 0.14 & 0.14 & 0.14 & 0.14 & 0.14 & 0.14 & 0.14 & 1.00 \\
\hline 2 & 0.2 & 0.2 & 0.2 & 0.2 & 0.0 & 0.0 & 0.2 & 1.00 \\
\hline 3 & 0.5 & 0.13 & 0.13 & 0.12 & 0.0 & 0.0 & 0.12 & 1.00 \\
\hline 4 & 0.25 & 0.125 & 0.125 & 0.125 & 0.125 & 0.13 & 0.125 & 1.00 \\
\hline 5 & 0.167 & 0.167 & 0.167 & 0.167 & 0.167 & 0.0 & 0.167 & 1.00 \\
\hline
\end{tabular}

Table 8 shows the final ranking results for the highest top four scoring LCH4 conditioner methods based on the various $\lambda$ scenarios that were used. Based on these relative rankings and total score data, it was decided to carry four densification methods into the second phase of development. It was found that for each $\lambda$ scenario, four basic systems came out on top: the Modified X-33 (Method 9) and the Direct TVS (Method 12) systems were generally the top two ranked methods while the Cryocooled Storage 
Vessel Densification (Method 23), the In-Situ External Limpet Coil (Method 13) and In-Situ Internal Helical Coil (Method 17) systems were also readily visible, especially from the safety perspective.

TABLE 8.-TOTAL SCORE VALUES ( $\Phi)$ FOR TOP FOUR HIGHEST RANKED LCH4 CONDITIONER METHODS

\begin{tabular}{|c|c|c|c|c|c|c|c|c|}
\hline $\begin{array}{c}\text { Importance } \\
\text { factor } \\
\text { distribution }\end{array}$ & $\begin{array}{c}\text { Total score } \\
\text { ranked } \\
\text { no. } 1\end{array}$ & $\begin{array}{c}\text { Method } \\
\text { ranked } \\
\text { no. 1 }\end{array}$ & $\begin{array}{c}\text { Total score } \\
\text { ranked } \\
\text { no. } 2\end{array}$ & $\begin{array}{c}\text { Method } \\
\text { ranked } \\
\text { no. } 2\end{array}$ & $\begin{array}{c}\text { Total score } \\
\text { ranked } \\
\text { no. 3 }\end{array}$ & $\begin{array}{c}\text { Method } \\
\text { ranked } \\
\text { no. 3 }\end{array}$ & $\begin{array}{c}\text { Total score } \\
\text { ranked } \\
\text { no. } 4\end{array}$ & $\begin{array}{c}\text { Method } \\
\text { ranked } \\
\text { no. } 4\end{array}$ \\
\hline 1 & 7.41 & $\begin{array}{c}\text { Modified } \\
\text { X-33, LCH4 }\end{array}$ & 7.38 & Direct TVS & 7.05 & $\begin{array}{c}\text { Slush } \\
\text { Methane }\end{array}$ & 6.89 & $\begin{array}{c}\text { In-situ } \\
\text { Limpet }\end{array}$ \\
\hline 2 & 7.62 & $\begin{array}{c}\text { Modified } \\
\text { X-33, LCH4 }\end{array}$ & 7.41 & $\begin{array}{c}\text { Slush } \\
\text { Methane }\end{array}$ & 7.30 & Cryocooler & 7.30 & Direct TVS \\
\hline 3 & 7.77 & Cryocooler & 7.20 & $\begin{array}{c}\text { Modified X- } \\
\text { 33, LCH4 }\end{array}$ & 7.15 & $\begin{array}{c}\text { Compact } \\
\text { H/E- Ar }\end{array}$ & 7.12 & In-situ Coil \\
\hline 4 & 7.29 & $\begin{array}{c}\text { Modified } \\
\text { X-33, LCH4 }\end{array}$ & 7.22 & Direct TVS & 6.97 & $\begin{array}{c}\text { In-situ } \\
\text { Limpet }\end{array}$ & 6.91 & $\begin{array}{c}\text { Co-current } \\
\text { H/E }\end{array}$ \\
\hline 5 & 7.48 & $\begin{array}{c}\text { Modified } \\
\text { X-33, LCH4 }\end{array}$ & 7.36 & Direct TVS & 7.23 & $\begin{array}{c}\text { Slush } \\
\text { Methane }\end{array}$ & 7.06 & In-situ Coil \\
\hline
\end{tabular}

From the down select, four conditioning methods were chosen for further evaluation during the Phase 2 study. The scope of the Phase 2 study will include the development of higher fidelity thermal models using CFD methods or their equivalent. Additionally, a cost analysis will be performed based on FY2012 projected dollars for the installation of the system, including all safety equipment as required for launch pad operational use. It is however unclear at this juncture if the Altair methane tanks would be capable of structurally handling the sub-atmospheric internal pressure ( 2 psia) that's required for the Direct TVS conditioning system without significant impact. This issue will be explored further during Phase 2 as well.

\section{Study Conclusions}

While storable propellants are still considered the baseline for the Altair ascent main engine, there is much interest in switching to a liquid oxygen/liquid methane (LOX/LCH4) engine to increase performance and thereby increase payload delivered to the lunar surface. Furthermore, the implementation of subcooled and densified LCH4 provides the capability for these flight tanks to perform throughout the entire mission with-out the need to vent. In support of the Altair ascent stage down-select between cryogenic (LOX/Methane) and hypergolic fuels (ETO/MMH), a Phase 1 conceptual study was conducted on the best ways to produce and deliver the liquid methane (LCH4) on-board the Altair vehicle in a densified state. The required temperature for densified liquid methane of $92.5 \mathrm{~K}\left(166.5^{\circ} \mathrm{R}\right)$ prior-toliftoff is associated with a saturation pressure of $13.8 \mathrm{kPa}(2 \mathrm{psia})$.

During this first phase of the engineering study, 26 different conceptual methods of production and delivery of densified LCH4 were analyzed with simple thermodynamic and mass models that were developed to check the feasibility of the system architectures. The densification methods were then ranked based on their safety, performance, flight and ground impacts, TRL, cost, and operational flexibility by team members from Fluid Systems (GRC and KSC), Shuttle Cryogenics (KSC) and Constellation Program (MSFC and KSC) disciplines.

The top four ranked methods were down-selected for further review and development of higher fidelity thermal modeling. Those methods chosen for further study during a Phase 2 effort were: a Modified X-33 densification system using liquid methane (Method 9); a Direct TVS on-the-pad vacuum pumping process system (Method 12); Cryocoolers integrated into a LCH4 storage tank (Method 23); and a secondary fluid heat exchanger via In-Situ Limpet Coil (Method 13) or In-Situ Helical Coil (Method 17) integrated into a liquid methane storage tank. The locations for each of these system architectures that would service Altair prior to launch would be locally mounted and potentially transportable GSE set-ups 
on the Mobile Launch Platform during propellant servicing. All of these methods have been briefly documented in this report for future reference to the aerospace community, while the conceptual design and operational details of the top four fuel conditioning methods selected will be expanded upon during the Phase 2 on-the-pad methane conditioning study. Some of the densification methods described in this paper are novel approaches not reported-on in the literature. In conclusion, the study team has high confidence that the four down-selected methane conditioning systems are judged to be the best solutions for Altair.

\section{References}

1. Tomsik, T.M., "Recent Advances and Applications in Cryogenic Propellant Densification Technology," NASA/TM-2000-209941, March 2000.

2. Moran, M.E., Haberbusch, M.S., and Satornini, G. A., "Densified Propellant Technology: Fueling Aerospace Vehicles in the New Era," AIAA-97-2824, July 1997.

3. LeMoyne, R., "Fundamental Analysis of Cryogenic Propellant Densification," AIAA-2008-2500, July 2008.

4. Lak, T.I., Lozano, M.E., and Tomsik, T.M., "Advancement in Cryogenic Propulsion System Performance Through Propellant Densification," AIAA Paper 96-3123, Presented at the $32^{\text {nd }}$ JPC, Lake Buena Vista, FL, July 1996.

5. Notardonato, W.U., "Densification of In-Situ Produced Propellants for the Human Exploration of Mars," AIAA-2002-4296, July, 2002.

6. Fazah, M.M., "STS Propellant Densification Feasibility Study Data Book," NASA TM-108467, September 1994.

7. Greene, W.D., and Boxx, D.L., "Propellant Densification for Shuttle: The SSME Perspective," AIAA-2002-3602, July 2002.

8. Tomsik, T.M., "Performance Tests of a Liquid Hydrogen Propellant Densification Ground Support System for the X33/RLV," NASA TM-107469, AIAA Paper 97-2976, Presented at the 33rd JPC, Seattle, WA, July 1997.

9. Greene, W.D., Knowles, T.B., and Tomsik, T.M., "Propellant Densification for Launch Vehicles: Simulation and Testing 1999," AIAA Paper 99-2335, June 1999.

10. Nguyen, K., Knowles, T.E., Greene, W.D., and Tomsik, T.M., "Propellant Densification for Launch Vehicles: Simulation and Testing," AIAA-2002-4293, July 2002.

11. Radebaugh R., Arman, B., Larson, K., Bradley, P., and Prazair Inc., "Pulse Tube Refrigerator for Hydrogen Densification," AIAA-2002-3600, July 2002.

12. Lak, T.I., Lozano, M.E., and Neary, D.A., "Propellant Densification Without Use of Rotating Machinery," AIAA-2002-3599, July 2002.

13. Haberbusch, M.S., Culler, A.J., DePhilips, D.P., Nguyen, C.T., Skaff, A.F., and Yeckley, A.J., "A New Densified Propellant Management System for Aerospace Vehicles," AIAA-2002-4294, July 2002.

14. Hardy, T.L., and Whalen, M.V., "Technology Issues Associated With Using Densified Hydrogen for Space Vehicles," AIAA 92-3079, July 1992.

15. Barsi, S., Moder, J., and Kassemi, M., "Numerical Investigation of LO2 and LCH4 Storage Tanks of the Lunar Surface," AIAA-2008-4749, Presented at the 2008 Joint Propulsion Conference and Exhibit, Hartford, CT, July 2008.

16. Johnson, W.L. "Launch Hold and Ascent Effects on Cryogenic Propellants," Level 1 Model Development Report, prepared for the Exploration Technology Development Program, Cryogenic Fluid Management Project, September 25, 2009.

17. Augustynowicz, S.D. and Fesmire, J.E., "Cryogenic Insulation System for Soft Vacuum," in Advances in Cryogenic Engineering, Vol. 45, Kluwer Academic/Plenum Publishers, New York, 2000, pp. 1691-1698. 
18. Cady, E., Cronick, J. et al. "LSTCS Final Scientific and Technical Report," NASA Contractor Report No. NNM08AA22C, September 30, 2009.

19. Mankins, J.C., "Technology Readiness Levels-A White Paper," Prepared for the Advanced Concepts Office, Office of Space Access and Technology, NASA Headquarters, Washington DC, April 6, 1995.

20. Larson et al. "Cooling of Cryogenic Liquids by Gas Injection," Advances in Cryogenic Engineering, Vol. 8, pp. 489-520.

21. Clark, J.A. Merte Jr., H., et al., "Pressurization of Liquid Oxygen Containers," Progress Report No. 18 UMRI Project 2646, Univ. of Mich. Research Inst. (October 1959).

22. Wu, W., Du, J. H., Lin, Y. R., Chow, L. C., and Notardonato, W., "Design and Experiment of Compact and Effective Carbon Foam Recuperative Heat Exchangers," Journal of Thermophysics and Heat Transfer, Vol. 23, No. 2, April-June 2009.

23. Jurns, J., Tomsik, T.M., and Greene, W.D., "Testing of Densified Liquid Hydrogen Stratification in a Scale Model Propellant Tank," (1999 Cryogenic Engineering and International Cryogenic Materials Conference, Montréal, Québec, Canada), NASA/TM-2001-209391, September 2001.

24. Doherty, M.P., Gaby, J.D., Salerno, L.J., and Sutherlin, S.G., "Cryogenic Fluid Management Technology For Moon and Mars Missions," AIAA-2009-6532, AIAA SPACE 2009 Conference and Exposition, Pasadena, CA, September 14-17, 2009.

25. NASA Glenn Research Center, Image Gallery Website, "Liquid Methane Tank," http://www.nasa.gov/centers/glenn/multimedia/imagegallery/if 54 methanetank.html, October 2009.

26. Salerno, L.J., "Reducing Launcher Mass with Zero Boil-Off or Densified Propellant Storage," presented at the French Cryogenic Society Meeting, Septieme Journees de Cryogenie et Supraconductivite, Aussois, France, May 2003.

27. Kepner, Charles, H. and Tregoe, Benjamin, B., "Kepner-Tregoe Decision-Making Website," http://www.decision-making-confidence.com/kepner-tregoe-decision-making.html 


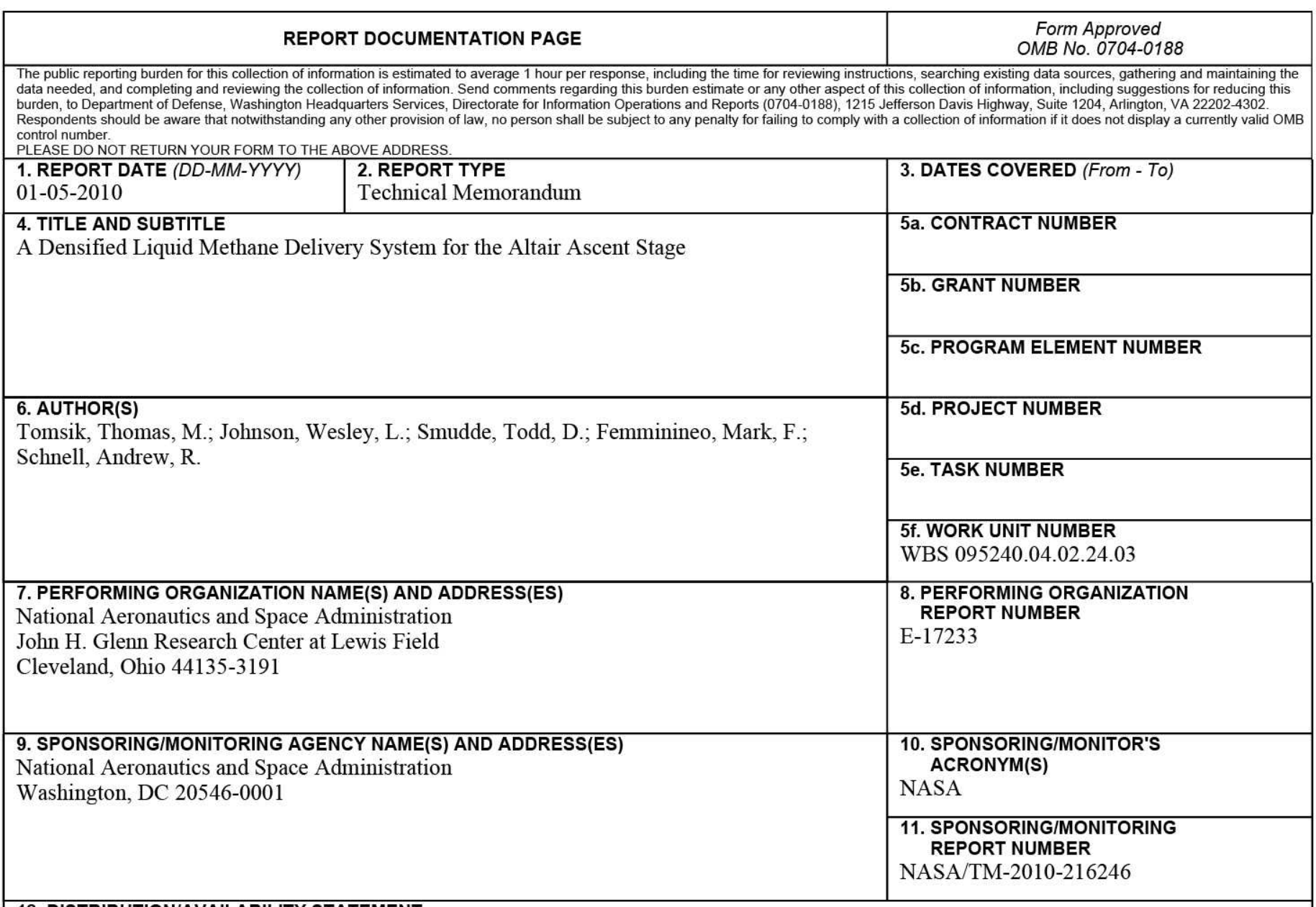

\section{DISTRIBUTION/AVAILABILITY STATEMENT}

Unclassified-Unlimited

Subject Categories: 14, 28, and 31

Available electronically at http://gltrs.grc.nasa.gov

This publication is available from the NASA Center for AeroSpace Information, 443-757-5802

\section{SUPPLEMENTARY NOTES}

\section{ABSTRACT}

The Altair Lunar Lander is currently carrying options for both cryogenic and hypergolic ascent stage propulsion modules. The cryogenic option uses liquid methane and liquid oxygen to propel Altair from the lunar surface back to rendezvous with the Orion command module. Recent studies have determined that the liquid methane should be densified by subcooling it to $93 \mathrm{~K}$ in order to prevent over-pressurization of the propellant tanks during the 210 day stay on the lunar surface. A trade study has been conducted to determine the preferred method of producing, loading, and maintaining the subcooled, densified liquid methane onboard Altair from a ground operations perspective. The trade study took into account the limitations in mass for the launch vehicle and the mobile launch platform as well as the historical reliability of various components and their thermal efficiencies. Several unique problems were encountered, namely delivering a small amount of a cryogenic propellant to a flight tank that is positioned over $350 \mathrm{ft}$ above the launch pad as well as generating the desired delivery temperature of the methane at $93 \mathrm{~K}$ which is only $2.3 \mathrm{~K}$ above the methane triple point of $90.7 \mathrm{~K}$. Over 20 methods of subcooled liquid methane production and delivery along with the associated system architectures were investigated to determine the best solutions to the problem. The top four cryogenic processing solutions were selected for further evaluation and detailed thermal modeling. This paper describes the results of the preliminary trade analysis of the 20 plus methane densification methods considered. The results of the detailed analysis will be briefed to the Altair Project Office and their propulsion team as well as the Ground Operations Project Office before the down-select is made between cryogenic and hypergolic ascent stages in August 2010.

\section{SUBJECT TERMS}

Densification; Methane; Cryogenic equipment; Cryogenic rocket propellants; Ground support equipment

\begin{tabular}{|c|c|c|c|c|c|}
\hline \multicolumn{3}{|c|}{ 16. SECURITY CLASSIFICATION OF: } & $\begin{array}{l}\text { 17. LIMITATION OF } \\
\text { ABSTRACT } \\
\text { UU }\end{array}$ & $\begin{array}{l}\text { 18. NUMBER } \\
\text { OF } \\
\text { PAGES } \\
37\end{array}$ & $\begin{array}{l}\text { 19a. NAME OF RESPONSIBLE PERSON } \\
\text { STI Help Desk (email:help@sti.nasa.gov) } \\
\text { 19b. TELEPHONE NUMBER (include area code) } \\
\text { 443-757-5802 }\end{array}$ \\
\hline
\end{tabular}



